\title{
Chemistry in supercritical fluids for the synthesis of metal nanomaterials
}

\author{
$\mathrm{Xu} Y{ }^{1}{ }^{1}$, Musumeci V. ${ }^{1}$, Aymonier C. ${ }^{1}$ \\ ${ }^{1}$ CNRS, Univ. Bordeaux, ICMCB, UMR 5026, F-33600 Pessac, France
}

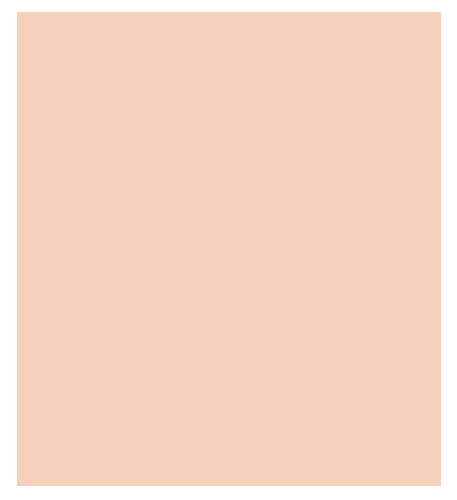

\section{ABSTRACT}

Metal nanomaterials are playing an increasingly important role in addressing challenges in modern society with respect to energy, catalysis, environment, information and so on. To maximize their performances in different application fields, fine control of their characteristics such as size and size distribution, morphology, composition, structure and surface properties is required. Suitable selection of the synthesis method for metal nanomaterials to achieve such control thus becomes rather important. In addition, the intent to use metal nanomaterials at a large scale puts extra expectations on the synthesis method that should be able to produce metal nanomaterials with high efficiency. Supercritical fluid synthesis of metal nanomaterials appears as a promising way to meet such needs thanks to the unique synthesis environment that speeds up the process but keeps the high controllability and reproducibility. In particular, supercritical fluid synthesis in flows enables continuous synthesis of metal nanomaterials and has high potential to be adapted into an industrial-level production process. This review focuses exclusively on the application of supercritical fluids in the synthesis of non-supported metal nanomaterials in both batch and flow reactors. Advancements in understanding the chemistry processes observed in the synthesis including thermolysis and reductive reactions in various types of fluids under their supercritical conditions are discussed and reviewed, with special attention to identifying the relationship between the properties of metal nanomaterials and the process parameters. Further, the versatility of the chemistry proceeding in supercritical fluids is shown by a few more examples on the synthesis of nanomaterials for applications in cutting edge technologies such as semiconductor nanocrystals, quantum dots, graphenic nanomaterials and metal-organic frameworks. Scaling up the supercritical fluid continuous flow synthesis to levels of pilot plants and even a full industrial plant has been achieved. The latest results and industrial progress in this area are discussed. Given this progress, the evaluation of the environmental impacts of the supercritical fluid flow synthesis becomes rather important. Finally, life cycle assessment (LCA) analysis is introduced as a powerful tool to evaluate the sustainability of chemical synthesis in supercritical fluids, shown by a few examples. 


\section{Introduction}

Metal nanomaterials are of significant importance to various areas including sustainable energy, green chemistry, heterogeneous catalysis, gas sensors, electronics and so on. For instance, there has been a long history of applying metal nanoparticles (hereafter metal NPs) as electrical conductors and electrode catalysts in fuel cells, electrochemical devices for direct generation of electricity from the chemical energy stored in fuels. Ni is known as a good catalyst for hydrogen oxidation and Ni-based porous cermets are the most commonly used anodes in solid oxide fuel cells. Bringing down Ni to nanosized dimensions results in improved performance thanks to the enhanced catalytic activity and in particular the increased density of the triple phase boundary, the active site for catalytic fuel oxidation in anodes. ${ }^{1-3}$ Despite their relatively high cost and scarcity, $\mathrm{Pt}, \mathrm{Pd}$ and $\mathrm{Ru}$ and their alloys are still among the most popular and reliable cathode catalysts for the oxygen reduction reaction (ORR) in protonexchange-membrane (PEM) fuel cells. ${ }^{4,5}$ Altering the morphology and thus exposing the favourable $\{111\}$ and $\{110\}$ planes of $\mathrm{Pt}$ at the nanoscale has been an effective way to design more active catalysts for the ORR. ${ }^{6}$ Metal nanoparticles are widely utilized as catalysts in the heterogeneous catalysis process of biomass refining and upgrading to more valuable biofuels. Lignin is one of the main components in woody biomass and is an interesting renewable source to produce various types of aromatic chemicals and biofuels. Such a conversion usually starts with the depolymerization of lignin, e.g. by metal-catalysed selective hydrogenolysis of the C-O bond in lignin, to produce derived model compounds that will be further transformed into more valuable chemicals.7-11 Among other metal catalysts under investigation, $\mathrm{Ni}_{85} \mathrm{Ru}_{15}$ showed a high catalytic activity at low temperature and $\mathrm{H}_{2}$ pressure $\left(100{ }^{\circ} \mathrm{C}, 1 \mathrm{bar}\right)$ in breaking the $\beta-\mathrm{O}-4$ type $\mathrm{C}-\mathrm{O}$ bond of lignin in water. 12 In addition, metal catalysts are also used in further refining and upgrading the derived model compounds. Such an example is shown in the utilization of catalysts made of Pd NPs supported on mesoporous N-doped carbon in the hydrodeoxygenation of vanillin in water. 100\% conversion and 100\% selectivity for 2-methoxy-4-methylphenol were achieved..$^{13}$ In the roadmap for hydrogen-based infrastructures, a number of issues have to be addressed including hydrogen production and purification. Methanol steam reforming serves as an interesting process to produce $\mathrm{H}_{2}$ from $\mathrm{H}_{2} \mathrm{O} / \mathrm{CH}_{3} \mathrm{OH}$ mixtures usually in the presence of heterogeneous catalysts. ${ }^{14} \mathrm{Cu}$-Based catalysts are commonly used to this end due to their high catalytic activity and selectivity to $\mathrm{CO}_{2}$. $\mathrm{CO}$, a typical by-product from side reactions in the production of $\mathrm{H}_{2}$, however, poisons Pt-based catalysts in PEM fuel cells and therefore has to be eliminated (less than $10 \mathrm{ppm}$ ) from the produced $\mathrm{H}_{2} \cdot{ }^{15} \mathrm{CO}$-selective methanation is regarded as an efficient method to do so, and Ni- and Ru-based catalysts are typically used for this purpose. ${ }^{16,17}$ Two of the feasible solutions to promote the reduction of greenhouse gases are hydrogenation of $\mathrm{CO}_{2}$ to synthesize $\mathrm{CH}_{3} \mathrm{OH}$ and dry reforming of $\mathrm{CH}_{4}$ with $\mathrm{CO}_{2}$ into syngas $\left(\mathrm{CO} / \mathrm{H}_{2}\right.$ mixture). Cu-Based catalysts are intensively investigated in the former, ${ }^{18-20}$ while $\mathrm{Ni}$-, Rh-, Ru- and Pt-based catalysts find significant uses in the latter. ${ }^{21,22}$

Metal nanomaterials are also very important for the development of resistive and electrochemical gas sensors displaying high sensitivity and selectivity towards the analyte gas, ${ }^{23,24}$ in line with a similar mechanism underlying selective catalysis. Pd-decorated oxides and carbon nanotubes, for instance, are of great interest in designing gas sensors to monitor $\mathrm{H}_{2} \cdot 25,26$ Flexible electronic devices are attracting increasing attention and they can be fabricated by printing inks made from metal nanoparticle colloids onto flexible substrates. They have a number of advantages such as high reproducibility and patterning properties and follow the philosophy of additive manufacturing. Inks made of $\mathrm{Au}, \mathrm{Ag}$ and $\mathrm{Cu}$ NPs are commercially available and mostly used since they are excellent electrical conductors and display good stability against oxidation. ${ }^{27,28}$

Nevertheless, it is not the aim here to make a complete review of all emerging applications of metal nanomaterials due to the intrinsic widespread interest over a remarkable amount of research. Accordingly, various types of synthetic methods have been developed that are customized to meet specific requirements on the properties of the synthesized metal nanomaterials and to facilitate integration of the metal nanomaterials into other materials and devices and syntheses to downstream processes. As will be discussed in the following paragraphs, methods among them that can be categorized into the wet chemical process are mostly applied, known as the bottom-up way, which uses metal atoms as building blocks and is advantageous in controlling the nucleation and growth and finally the size, shape, phase and so on to a very high level. ${ }^{29-33}$

Seed-mediated synthesis has appeared as a very efficient way to prepare non-spherical metal NPs in different forms including rods, wires, rectangles, cubes, plates, disks and so on. ${ }^{34,35}$ In a typical process, the preformed fine metal NPs called seeds are added to a solution and serve as sites for the following heterogeneous nucleation and growth of metal nanostructures. For example, single-crystalline Pd NPs in shapes of rhombic dodecahedra, cubes and octahedra are prepared by this method through selective growth of facets regulated by a surfactant 
(potassium iodide) and temperature. ${ }^{36}$ The solvothermal process is also widely observed in the synthesis of metal nanomaterials. Metal precursors, either metal salts or metal organic compounds, are dissolved in solvents. Reductants (e.g. hydrogen, hydrides, alcohols, citric acid) are often used to reduce the metal cations to the corresponding metals, in which the reduction process is usually promoted by heating. Surfactants $(e . g$. oleylamine, thiols, polyvinylpyrrolidone, ionic liquids) are typically employed for purposes of tuning the size and morphology as well as stabilizing the synthesized NPs. ${ }^{29,32,37}$ Alternatively, the reduction can also take place through electrical discharges and electron donors excited by photons. These therefore bring up the so-called electrochemical and photochemical methods, respectively. ${ }^{29,31,32}$ The latest trend in the development of synthesis methods for metal nanomaterials takes into consideration the environmental impact by using extracts from plants and other natural biomolecules to meet the increasingly strict environmental regulations in the chemical industry. 38,39

Despite these methods having shown extraordinarily fine control on the process to obtain metal nanomaterials with desired properties, a common observation is that these methods are conducted on a small scale typically at the laboratory level, relatively slow in process and less likely to be scaled up to industrial manufacturing. Using supercritical fluids to replace the conventional reaction media is getting more and more attention in the synthesis of nanomaterials including metal nanomaterials, among other endeavours to search for new methods that can speed up the process while keeping the controllability high. Fluids are in their supercritical conditions (Fig. 1) ${ }^{40}$ when both the temperature and the pressure are above the critical points that vary from one to the other (Table 1). ${ }^{41}$ Distinct from fluids in liquid or gas form, supercritical fluids display interesting physicochemical properties, such as solvation behaviour, dielectric properties, and rather low viscosity and surface tension but high diffusivity, which abruptly change close to the critical points and are readily altered by the temperature and pressure. Supercritical fluids, especially $\mathrm{H}_{2} \mathrm{O}$ and $\mathrm{CO}_{2}$, have found wide applications as supercritical water oxidation, biomass gasification and liquefaction, extraction, green chemical processes and chemical recycling of plastics and composite materials. ${ }^{42-45}$

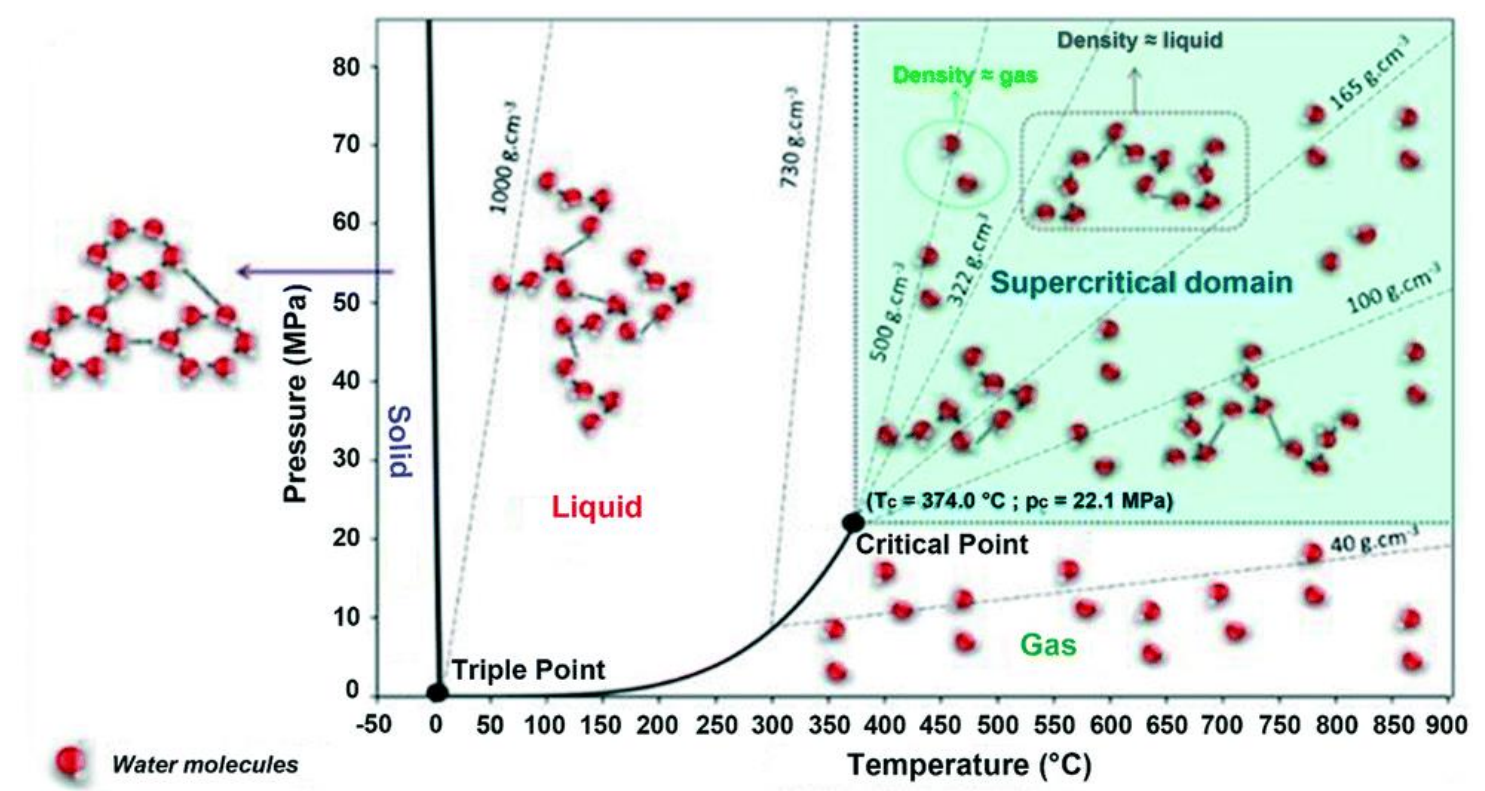

Fig. 1 The phase diagram of a fluid, with water as an example. Reprinted with permission from ref. 40. Copyright 2010 J. Wiley.

With these distinct physicochemical properties, supercritical fluids become the preferred media for synthesizing nanomaterials. In supercritical fluids, the process proceeds faster than in liquids thanks to the enhanced reaction rate. Nucleation and growth of nanomaterials are promoted by tuning the solvation behaviour of supercritical fluids in a wide range to rapidly achieve the supersaturation of solutes. In addition, typically a homogeneous reaction environment in supercritical fluids can be created as supercritical fluids dissolve a broad range of chemicals including reductants, oxidants and surfactant molecules. This also allows for fine tuning of surface properties of synthesized nanomaterials..$^{48-52}$

The interest in applying supercritical fluids to synthesize nanomaterials has been continuously increasing, as shown in particular by three main advancements of material processing techniques utilizing supercritical fluids. The first is 'continuous solvo-/hydrothermal flow synthesis' which makes continuous flow production of nanomaterials and thus a high production rate possible, thanks to the remarkably enhanced solvo-/hydrothermal 
reaction rate in supercritical solvents. ${ }^{41,53-55}$ Such representative examples have been presented in works on synthetic minerals. In comparison with the formation of natural minerals over geological time in ranges of millions of years, such minerals are synthesized in labs within batch reactors mimicking the natural environment in days to hours. Further, the time can be substantially reduced to only tens of seconds by conducting the mineral synthesis in supercritical water in continuous flow-type setups. ${ }^{56-59}$ The second is 'supercritical fluid reactive/chemical deposition (SFRD/SFCD)' which takes advantage of the good capabilities of supercritical fluids in diffusion and mass transport. It is particularly suitable to achieve homogeneous and conformal deposition of nanomaterials on substrates with complex topographies and ultrafine microstructures. ${ }^{60-65}$ The third is 'supercritical microfluidics' which runs supercritical fluid synthesis of nanomaterials in 'on-chip' microsystems with good control on process conditions and high reproducibility. Examples of such advantages in material synthesis are shown in the synthesis of semiconductor nanocrystal quantum dots (QDs) whose optical and electronic properties are primarily dependent on the size and crystallinity. Highly uniform CdSe QDs in a very narrow size distribution $(2.7 \mathrm{~nm}, \sigma \leq 5 \%)$ were obtained by this method in supercritical hexane in continuous flow with a high production rate. ${ }^{66} \mathrm{GaN}$ QDs of about $3 \mathrm{~nm}$ were also synthesized by this method in supercritical cyclohexane and a mixture of hexane and ammonia. A narrower FWHM $(0.5 \mathrm{eV})$ of peaks in photoluminescence emission spectra than usual $(>0.65 \mathrm{eV})$ implies that the obtained GaN QDs have a narrow size distribution and high quality. ${ }^{67}$ In addition, supercritical microfluidics is noticeably useful for in situ and online characterization of processes in supercritical fluids. ${ }^{41,68,69}$

It is worth mentioning here, however, that materials used to fabricate such microfluidic reactors should be able to withstand conditions of high temperature and pressure for supercritical fluid-based processes (Table 1). Therefore, materials that are usually applied in making microfluidic systems such as polydimethylsiloxane (PDMS) cannot be used to this end due to their poor temperature and pressure resistance. ${ }^{70}$ Instead, metals can be used in constructing microfluidic reactors for supercritical fluid processes, ${ }^{71-73}$ as have been used intensively in most of the research studies summarized in this review. Very high heating rates and isothermal temperature profiles could be achieved with such microreactors, which is advantageous to applications such as endothermic thermal gasification and reforming of biomass components. ${ }^{71,72}$ For in situ analysis of supercritical fluid processes, optically transparent materials such as glass ${ }^{74-76}$ and silicon-based materials ${ }^{68,77}$ are typically applied. In addition, microfluidic reactors made of glass and silicon-based materials enable modification of the wettability of the channels by modifying the surface in silane chemistry. ${ }^{70,78-80}$

Applying supercritical fluids to the synthesis and processing of nanomaterials has become a very active research field, and numerous results related to different types of nanomaterials have been reported in the past few decades. Indeed, there have been a number of reviews on the synthesis and processing of nanomaterials in supercritical fluids that mostly focused on oxides, nitrides, sulphides, metal-organic frameworks, supported metals and composites. ${ }^{41,54,55,61,81-84}$ To the best of our knowledge, however, there has not been a thorough review exclusively targeting the synthesis and processing in supercritical fluids of non-supported metal nanomaterials and systems based on colloidal metal nanoparticles. Therefore, this review focuses exclusively on the progress in applying supercritical fluids to the synthesis and processing of non-supported metal nanomaterials and tailoring their colloidal stability. The performances of metal nanomaterials in various applications are highly dependent on their properties, including size and size distribution, morphology, structure and composition. Whenever available, special efforts are made to highlight the exceptional control of the supercritical fluid synthesis process for tailoring metal nanomaterials with desired properties. In summary, Table 2 provides an overview of the nonsupported metal nanomaterials that have been reported on synthesis using supercritical fluids. 
Table 1 Critical points $\left(T_{c}, p_{c}\right)$ of several fluids ${ }^{41,46,47}$ used in the synthesis of metal nanomaterials

\begin{tabular}{llc}
\hline & $T_{\mathrm{c}}\left({ }^{\circ} \mathrm{C}\right)$ & $p_{\mathrm{c}}(\mathrm{MPa})$ \\
\hline $\mathrm{H}_{2} \mathrm{O}$ & 374 & 22.06 \\
$\mathrm{CO}_{2}$ & 31 & 7.38 \\
Methanol & 239 & 8.1 \\
Ethanol & 241 & 6.27 \\
Acetone & 235.1 & 4.7 \\
$\mathrm{NH}_{3}$ & 132 & 11.33 \\
Hexane & 235 & 3.03 \\
Octanol & 385 & 3.45
\end{tabular}

The first part of the review focuses on the different methods related to the use of supercritical fluids in the synthesis of metal nanomaterials. In each method, special attention is put on how the processing parameters can alter the properties of the synthesized metal nanomaterials. Whenever available, the unique advantages of conducting the chemistry in supercritical fluid flows are compared and highlighted. Afterwards, results of the reaction, nucleation and growth of metal nanomaterials in supercritical fluids at different stages revealed by in situ techniques are reviewed and summarized. Later, we emphasize the versatility of the chemistry in supercritical fluids and its importance to nanomaterials and nanotechnology in the future by highlighting a few more examples on the synthesis of nanomaterials including semiconductor nanocrystals, quantum dots, graphenic materials and metal-organic frameworks, all prepared via a continuous flow process with a high production rate. In this regard, efforts on scaling up the supercritical fluid flow synthesis to pilot and full industrial levels are then reviewed. Further, there have been some research studies in recent years on evaluating the environmental impact of supercritical fluid synthesis of nanomaterials by life cycle assessment (LCA) which takes into consideration all the associated stages of the process. This could be inspiring to future developments and progress in supercritical fluid synthesis and processing of nanomaterials to meet the demands of reducing impacts on the environment and improving sustainability in the field of chemical engineering. Fig. 2 provides a simple scheme of the contents under focus in this article.

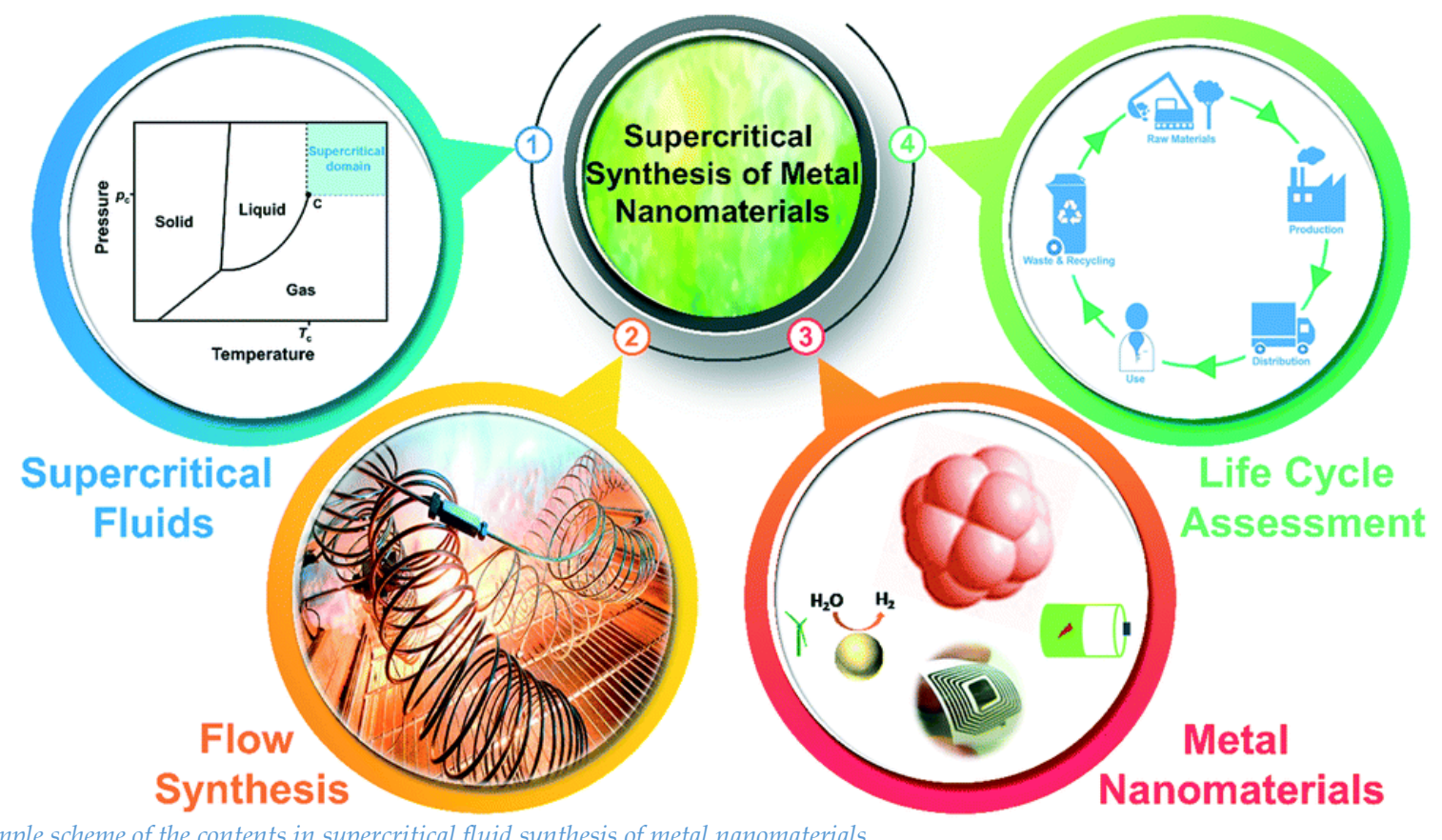

Fig. 2 A simple scheme of the contents in supercritical fluid synthesis of metal nanomaterials. 


\section{Thermolysis in supercritical fluids}

When a supercritical fluid is used as the reaction medium, the reaction rate will be significantly enhanced and the reaction time can thus be reduced to a large extent, giving access to the flow chemistry process. Indeed, this is particularly interesting to flow chemistry synthesis where the reaction as well as the nucleation and growth of nanomaterials proceed in a continuous stream. ${ }^{41,55-58,121}$

To this end, mainly two families of designs have been adopted, in both of which the dwelling time of the synthesis process can be finely tuned in the range of seconds to minutes. One is by thermally decomposing a precursor flow in a reactor at controlled temperatures and pressures above the critical points of solvents (type I in Fig. 3), and the other is by rapidly heating up a room-temperature precursor flow when it is brought to mix with a supercritical fluid flow prior to entering a reactor (type II in Fig. 3). In the first design (type I in Fig. 3), metal compound precursors dissolved in solvents are typically taken and metal nanomaterials can be obtained through the thermolysis of precursors in supercritical solvents. The nature of precursors and solvents largely influences the properties of the product nanomaterials.

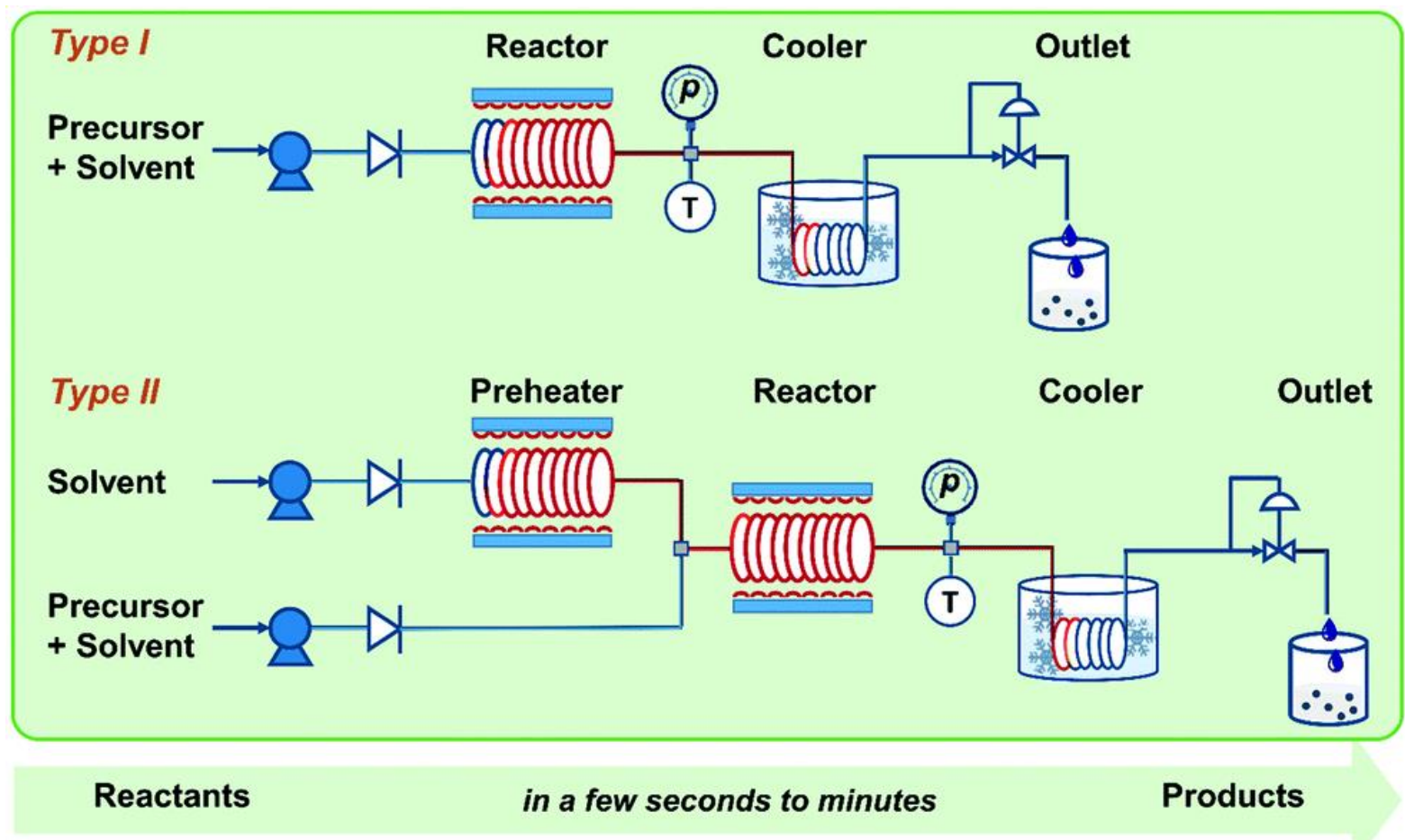

Fig. 3 Simple schemes of the two types of apparatus utilized for the continuous flow synthesis of nanomaterials in supercritical fluids. The main process parameters include the solvent, precursor, flow rate, temperature $(T)$, pressure $(p)$ and residence time $(\tau)$.

For example, Pd NPs with a fairly narrow size distribution and high reactivity were synthesized in flows from several types of metal precursors decomposed in supercritical acetone $\left(250{ }^{\circ} \mathrm{C}, 20 \mathrm{MPa}\right) .85,86 \mathrm{Pd}$ is $\mathrm{known}$ for acting as the catalytic active material in decomposing formic acid122 and in carbon-carbon coupling reactions123 and displaying a high affinity to hydrogen in gas sensing and storage.124,125 The precursors under focus included Pd(ii) bis(acetate), Pd(ii) bis(acetylacetonate), Pd(ii) bis(trifluoroacetate) and Pd(ii) bis(hexafluoroacetylacetonate). It was found that the type of precursor affects the size and agglomeration state of the as-synthesized Pd NPs (Fig. 4a-d).85 


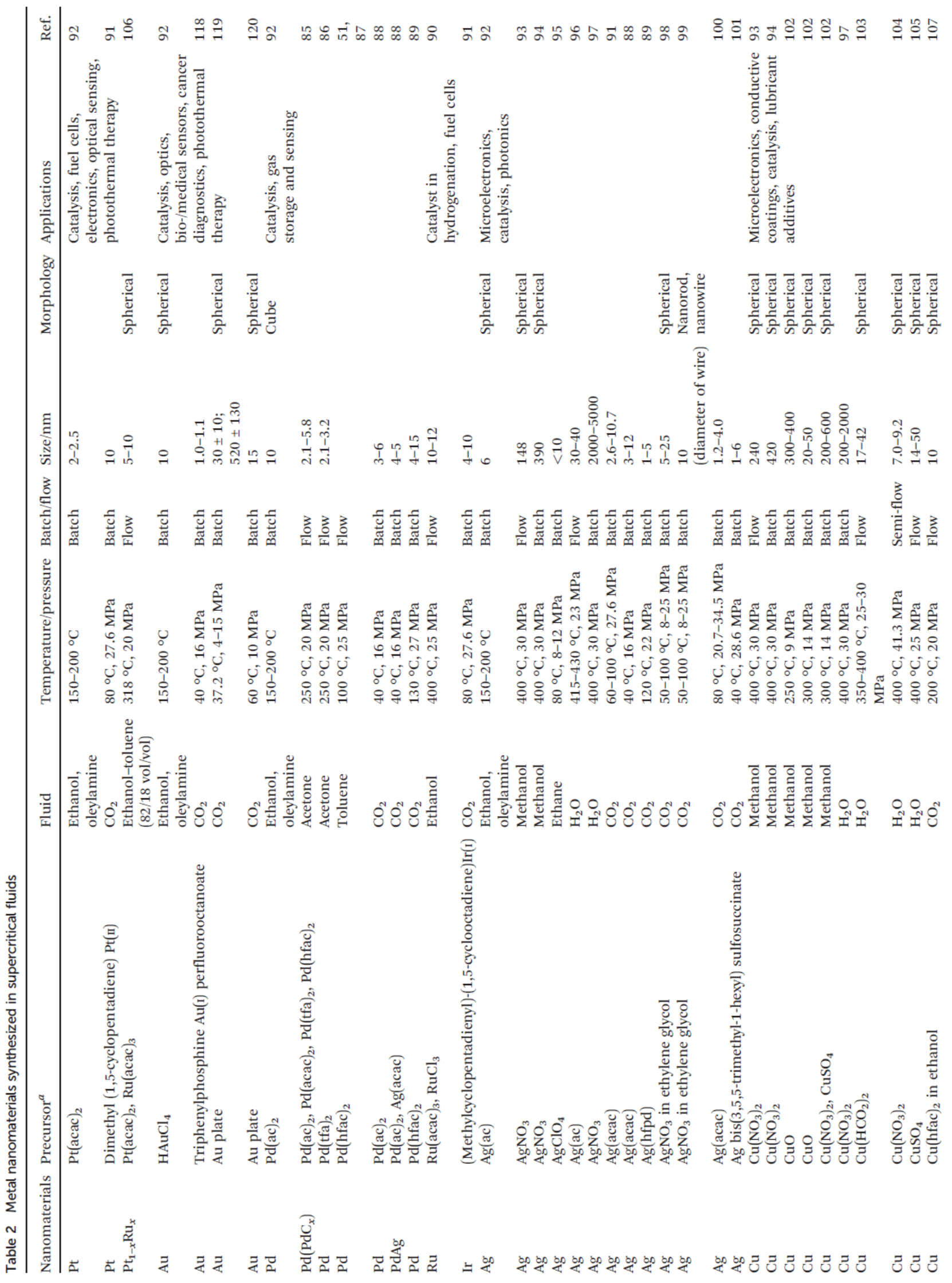




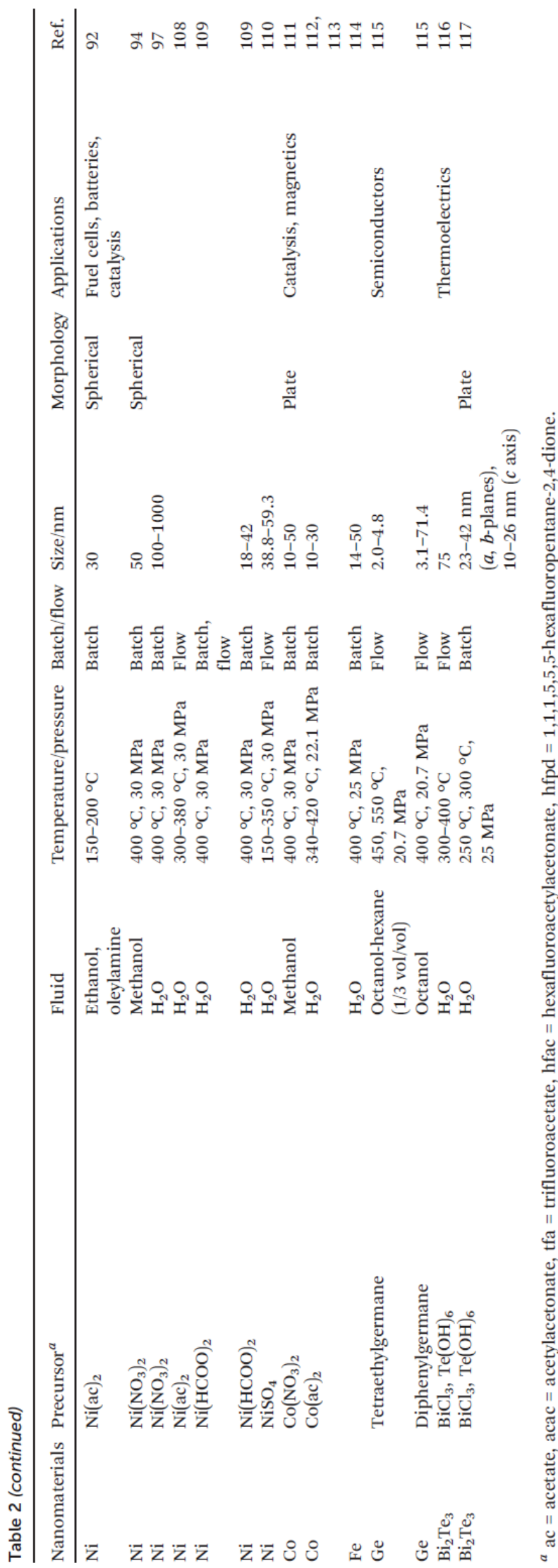


A similar process in supercritical solvents of hexane and octanol $\left(400-450^{\circ} \mathrm{C}, 20.7 \mathrm{MPa}\right)$ was adopted for the synthesis of Ge nanocrystals, in which two types of precursors were studied, i.e. tetraethylgermane and diphenylgermane. ${ }^{115}$ The thermolysis of both precursors in supercritical hexane simply resulted in bulk polycrystalline Ge in micrometres. However, by adding supercritical octanol ( $25 \mathrm{vol} \%)$ as the co-solvent to the synthesis, Ge NPs were obtained from the thermolysis of tetraethylgermane. The size of the particles was reduced to 2.0-4.8 nm which was nearly independent of the precursor concentration. In comparison, a rather narrow window of conditions was required to obtain Ge NPs when diphenylgermane was used due to its higher reactivity, in which pure octanol and relatively mild conditions $\left(400^{\circ} \mathrm{C}\right.$, a short reaction time of $20 \mathrm{~s}$ ) were necessary. Despite that, the particle size could be largely tuned between $3 \mathrm{~nm}$ and $71 \mathrm{~nm}$ with the concentration of diphenylgermane.

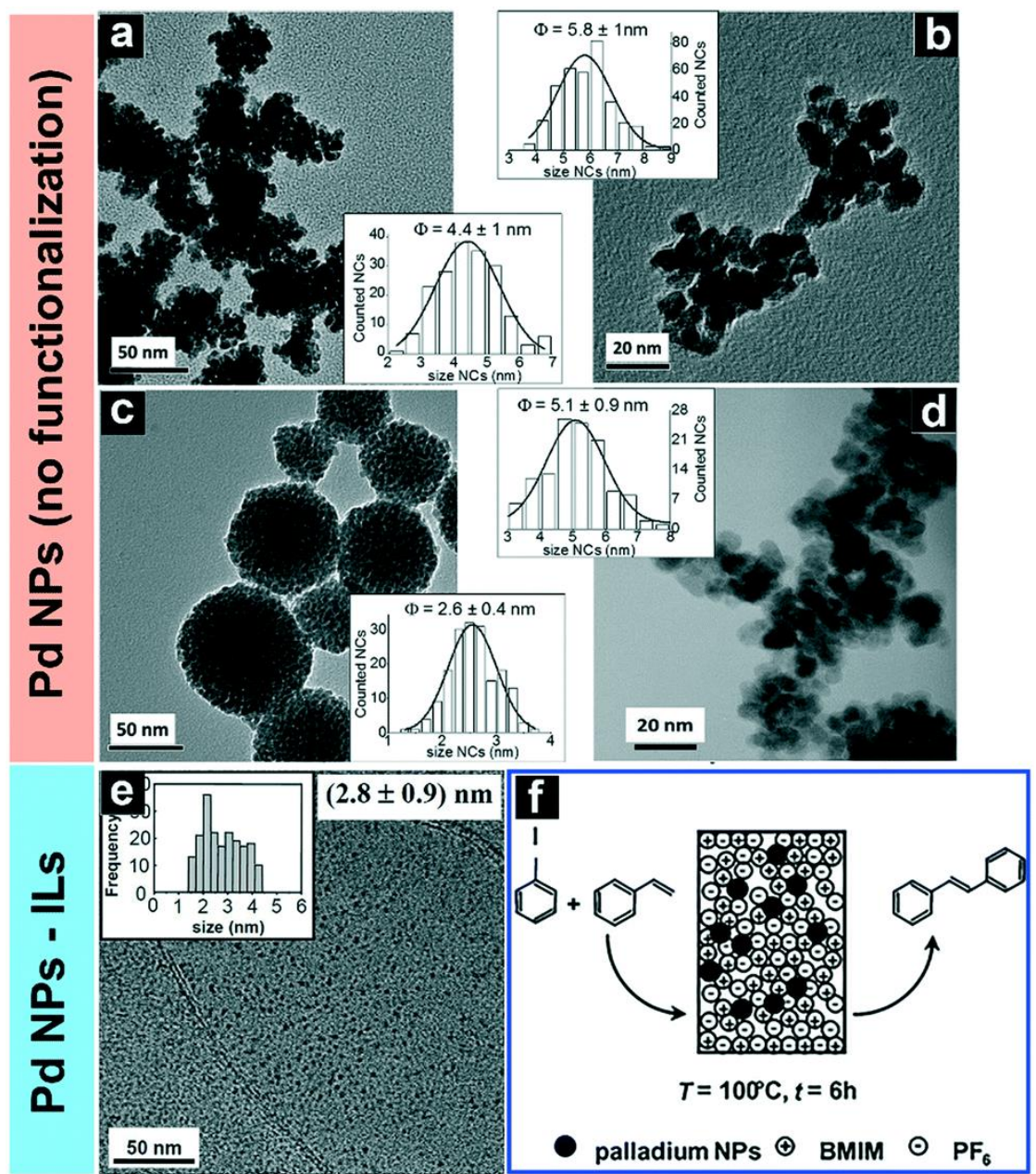

Fig. 4 The first two lines show Pd NPs synthesized from different precursors in supercritical acetone with different sizes and agglomeration states. (a) Pd(ii) bis(acetate), (b) Pd(ii) bis(acetylacetonate), (c) Pd(ii) bis(trifluoroacetate) and (d) Pd(ii) bis(hexafluoroacetylacetonate). Reprinted with permission from ref. 85. Copyright 2014 American Chemical Society. The third line shows (e) crude Pd NPs ex situ functionalized and stabilized by BMIMPF6, a type of ionic liquid (IL), synthesized from Pd(ii) bis(trifluoroacetate) in supercritical acetone and (f) the application in catalysing the Heck reaction. Reprinted with permission from ref. 86. Copyright 2008 Royal Society of Chemistry.

Si particles especially those in-between 75 and $200 \mathrm{~nm}$ are interesting for optical applications, being used as building blocks for metamaterials thanks to their electromagnetic properties that are highly dependent on the size, composition and shape of the particles. ${ }^{126}$ Among others, thermolysis of Si precursors in supercritical solvents has been explored to produce such Si particles with the aim to achieve high controllability. The type of precursor plays an important role in the properties of Si particles. For example, from the thermolysis of trisilane $\left(\mathrm{Si}_{3} \mathrm{H}_{8}\right)$ in supercritical $n$-hexane $\left(400-500^{\circ} \mathrm{C}, 127380-550{ }^{\circ} \mathrm{C}^{128}\right)$, colloidal amorphous Si particles were obtained which are spherical, non-agglomerated and monodispersed. The particle size (50-500 nm,127 170 nm-1.7 $\left.\mu{ }^{128}\right)$ was sensitive to the concentration of the precursor and a higher concentration resulted in a larger average particle size. In comparison, well-crystallized Si quantum dots (1.5-4 nm) were obtained from the thermolysis of diphenylsilane in a supercritical mixture of $n$-hexane and 1-octanol $\left(500{ }^{\circ} \mathrm{C}\right) .{ }^{129}$ As observed, the temperature and 
pressure should also be manipulated as they have an effect on the structure of the amorphous Si colloids including the hydrogen content and bond order. ${ }^{128}$ With an increased temperature, the structure order was increased, whereas the hydrogen content was reduced.

The advantages of applying the supercritical fluid as the reaction medium for the thermolysis have been shown in two aspects. Firstly, ultra-small and reactive NPs can be obtained through the synthesis. This was observed by the formation of Pd NPs of less than $3 \mathrm{~nm}$ from the decomposition of palladium metal precursors in supercritical acetone, where the dissolution of $\mathrm{C}$ into the lattice of the active Pd nanocrystals resulting in carbides happened even at room temperature. ${ }^{85}$ Secondly, high controllability of particle characteristics can be achieved by tuning process parameters such as temperature, pressure, residence time and nature of reactants in the absence of in situ functionalization agents during the supercritical fluid synthesis. ${ }^{115,130,131}$ Given that, in addition to the in situ functionalization, it is also possible to separate the particle synthesis process from the surface functionalization step, named ex situ functionalization, providing a rather flexible selection of functionalization agents applied right after the synthesis of crude particles for various purposes.81,86,132 For instance, by directly spraying the roomtemperature outflow containing crude Pd NPs from the decomposition of palladium bis(trifluoroacetate) in supercritical acetone to the solutions of functionalization agents (e.g. a thiol ${ }^{85,86}$ and an ionic liquid $\left.{ }^{86}\right)$, fairly small and highly monodispersed Pd NPs $(2.1 \pm 0.4 \mathrm{~nm}$ with the thiol and $2.8 \pm 0.9$ with the ionic liquid) were stabilized without forming aggregates. The colloidal stability of the thiol-capped Pd NPs was tested in a perfluoro solvent and displayed good stability over several weeks. In addition, the ionic liquid functionalized Pd NPs were active in catalysing the Heck reaction between iodobenzene and styrene and the turnover number was 2500 (Fig. 4e and f).

Here, it has been shown that metal nanomaterials with controlled properties can be successfully made through the thermolysis of metal precursors in supercritical solvents. The nature of both precursors and solvents has a large impact on the properties of the metal products, in addition to parameters such as the temperature and the precursor concentration. Special attention has been given to adapting this method to the continuous supercritical fluid technique which speeds up the fabrication of metal nanomaterials, due to the enhanced reaction rate and thus shortened reaction time in flow processes. The use of supercritical fluids also enriches the selection of functionalization agents. Besides being used in situ during the synthesis to modify the properties of metal nanomaterials, the functionalization agents can also be introduced separately (ex situ) after the synthesis of nanomaterials with pre-defined characteristics thanks to the good controllability in supercritical fluids.

\section{Reductive reactions in supercritical fluids}

Simply considering that the process principle of synthesizing metals includes a reduction step to the zero-valence state, it is straightforward to introduce a reducing agent into the synthesis. This can be achieved in two ways, either by taking advantage of supercritical solvents with a reducing power (section 3.1) or by adding reductants (section 3.2). In the second case, the choice of solvent is enriched since those without reducing power such as supercritical $\mathrm{H}_{2} \mathrm{O}$ and $\mathrm{CO}_{2}$ can be used as well for preparing pure metal NPs.

\section{Reductive supercritical solvents}

Some organic solvents such as low-carbon-number alcohols (mainly methanol and ethanol) can act as electron donors so as to be used to obtain pure metal NPs without the need of adding extra reductants. $.32,92$ These alcohols undergo decomposition as the temperature increases, and complex reactions proceed among the by-products, including the aldol reaction, resulting in chain elongation. In both cases of methanol and ethanol decomposition, however, dehydrogenation is a key step. In addition, a significant amount of gases, in which hydrogen and carbon monoxide account for $40-50 \%$ of the total yield, is produced at high temperatures, under supercritical conditions in particular. ${ }^{47} \mathrm{~A}$ favourable reductive environment is therefore created from the viewpoint of synthesis of metal nanomaterials. In addition, these alcohols contain hydroxyl groups, and some free hydroxyl ions might be present from the dissociation at increased temperatures which also display reduction capability. ${ }^{93,102,133}$ 
As such, from the corresponding metal nitrate salts solubilized in supercritical methanol $\left(400{ }^{\circ} \mathrm{C}, 30 \mathrm{MPa}\right)$ sealed and placed in autoclaves for $300 \mathrm{~s}$, pure $\mathrm{Ni}, \mathrm{Cu}$ and $\mathrm{Ag}$ particles were obtained with a spherical morphology and average diameters of $50 \pm 10 \mathrm{~nm}, 420 \pm 119 \mathrm{~nm}$ and $390 \pm 114 \mathrm{~nm}$, respectively. ${ }^{94}$ As mentioned earlier, the supercritical synthesis conditions enable a much faster reaction rate than that in the conventional solvothermal environment. An adaptation to the flow synthesis system (type II in Fig. 3) while maintaining the use of supercritical methanol $\left(400^{\circ} \mathrm{C}, 30 \mathrm{MPa}\right)$ significantly brought down the reaction time to only $17 \mathrm{~s}$, while pure $\mathrm{Cu}$ and $\mathrm{Ag}$ powders with decreased average diameters ( $240 \mathrm{~nm}$ and $148 \mathrm{~nm}$, separately) were obtained. ${ }^{93}$ Hardly phase-pure Ni was obtained, mainly due to its relatively high reductivity and the reduction from $\beta-\mathrm{Ni}(\mathrm{OH})_{2}$ intermediates taking a longer time than that of the flow system. The reduction in methanol was found to be enhanced with the increase of temperature, as was proven by the gradually reduced amount of hydroxide, oxynitrate or oxide by-products left in the final products. $93,102,111$ When the same reductive solvent is used, the minimum temperature required for a full reduction to obtain pure metals from nitrates steadily increases for metals with different reductive abilities, in the sequence $\mathrm{Ag}\left(150{ }^{\circ} \mathrm{C}\right),{ }^{93} \mathrm{Cu}\left(300^{\circ} \mathrm{C}\right), 93,102 \mathrm{Ni}\left(400{ }^{\circ} \mathrm{C}\right),{ }^{93}$ and $\mathrm{Co}(400$ $\left.{ }^{\circ} \mathrm{C}\right) .111 \mathrm{O}$ On the other hand, varying the reaction time and analysing the phase compositions of products shed light on the metal formation process. The time-resolved contents of metal-oxynitrate, hydroxide and/or oxide intermediates indicate that the metal cations first react with hydroxyl ions that have strong reductivity and are formed by the temperature-dependent decomposition of alcohols. ${ }^{102,111}$

The as-synthesized metal particle properties with respect to the size and morphology are affected by the type of precursor, as demonstrated in the synthesis of $\mathrm{Cu}$ in supercritical methanol. ${ }^{102} \mathrm{CuO}$ used as the precursor resulted in much smaller and more spherical $\mathrm{Cu}$ particles compared with those obtained from $\mathrm{Cu}\left(\mathrm{NO}_{3}\right)_{2}$ or $\mathrm{CuSO}_{4}$ (Fig. 5). The type of precursor also influences the reaction kinetics of precursors being reduced by alcohols. For instance, it takes a shorter time to obtain $\mathrm{Cu}$ from $\mathrm{CuSO}_{4}$ than from $\mathrm{Cu}\left(\mathrm{NO}_{3}\right)_{2}$ in supercritical methanol under identical conditions $\left(250{ }^{\circ} \mathrm{C}, 9 \mathrm{MPa}\right),{ }^{102}$ as it did to obtain $\mathrm{Ru}$ from $\mathrm{RuCl}_{3}$ than from $\mathrm{Ru}$ (iii) tri(acetylacetonate) in supercritical ethanol $\left(400^{\circ} \mathrm{C}, 25 \mathrm{MPa}\right) .{ }^{90}$ The solvent also has an impact on the characteristics of the synthesized metal NPs. For example, although methanol forms a stronger reducing environment than ethanol at the same temperature and pressure, ${ }^{102} \mathrm{Ag}$ NPs synthesized in supercritical ethanol however were smaller and more uniform than those synthesized in supercritical methanol. ${ }^{94}$

Another advantage of adapting the supercritical fluid synthesis to the flow-type apparatus with a significantly reduced reaction time is that it enables high-throughput synthesis of a series of nanomaterials and screening of their properties in relation to the process parameters. ${ }^{134-139}$ Alloying Pt with relatively cheaper elements such as $\mathrm{Ru}$ has been regarded as a feasible way to reduce the cost of high-efficiency catalysts and to improve the resistance against $\mathrm{CO}$ poisoning of the Pt-based catalysts. The stoichiometry of alloys however becomes rather important with respect to optimizing the catalytic performance. To this end, a group of $\mathrm{Pt}_{1-x} \mathrm{Ru}_{x}(0 \leq x \leq 1) \mathrm{NPs}$ were synthesized in supercritical ethanol-toluene flows $\left(318^{\circ} \mathrm{C}, 20 \mathrm{MPa}\right)$ with an entire range of stoichiometric compositions in a step difference of $10 \mathrm{~mol} \% .{ }^{106}$ Note that the synthesis period for each composition fells in only 6-11 s. Alloy NPs with uniform compositions were achieved which were tailorable by altering the composition of metal precursors. The particle size (5-10 nm), one of the important factors of the catalytic performance, was found to decrease with increasing Ru content. In addition, only particles with the single face-centered cubic phase were obtained with compositions of $x<0.3$, whereas particles with compositions $(x)$ between 0.3 and 1.0 were in dual phases, namely the face-centered cubic (fcc) and the hexagonal closed-packed (hcp).

Ionization of supercritical ethane through radiolysis induced by a pulse of high-energy electrons can generate free electrons available to reduce $\mathrm{Ag}$ cations ${ }^{95}$ Methanol as the co-solvent with the dissolved $\mathrm{AgClO}_{4}$ precursor formed clusters that were dispersed within supercritical ethane. Ag was formed by the reduction reaction within the clusters between $\mathrm{Ag}$ cations and the solvated electrons from the pulse radiolysis. Without using stabilizers, colloidal Ag NPs $(<10 \mathrm{~nm})$ were obtained with suppressed aggregation in supercritical ethane, partly due to the limited size and mobility of the methanol clusters in supercritical ethane.

In conclusion, supercritical organic fluids, in particular low-carbon-number alcohols, serve as suitable reaction media for synthesizing metal nanoparticles without the need of adding extra reducing agents. The fact that the solvents decompose when temperature increases is made use of to form a favourable reductive environment. As a stronger reducing atmosphere is created at a higher temperature, the minimum temperature for obtaining pure metals from reduction reactions varies for metals with different reductive abilities. The nature of metal precursors impacts not only their capability of being reduced but also the properties (e.g. size and morphology) of the synthesized metal nanomaterials. Besides, solvents have effects on the properties of the synthesized metals, in addition to their different reducing powers in nature. Transferring the reductive synthesis of metal nanomaterials 
in supercritical solvents from batch reactors to continuous flow-type systems is achieved, where smaller metal nanoparticles can be obtained in a significantly reduced reaction time. The shortened reaction period also enables a high-throughput synthesis of a set of metal nanomaterials to study the relationship among properties, structure and composition.
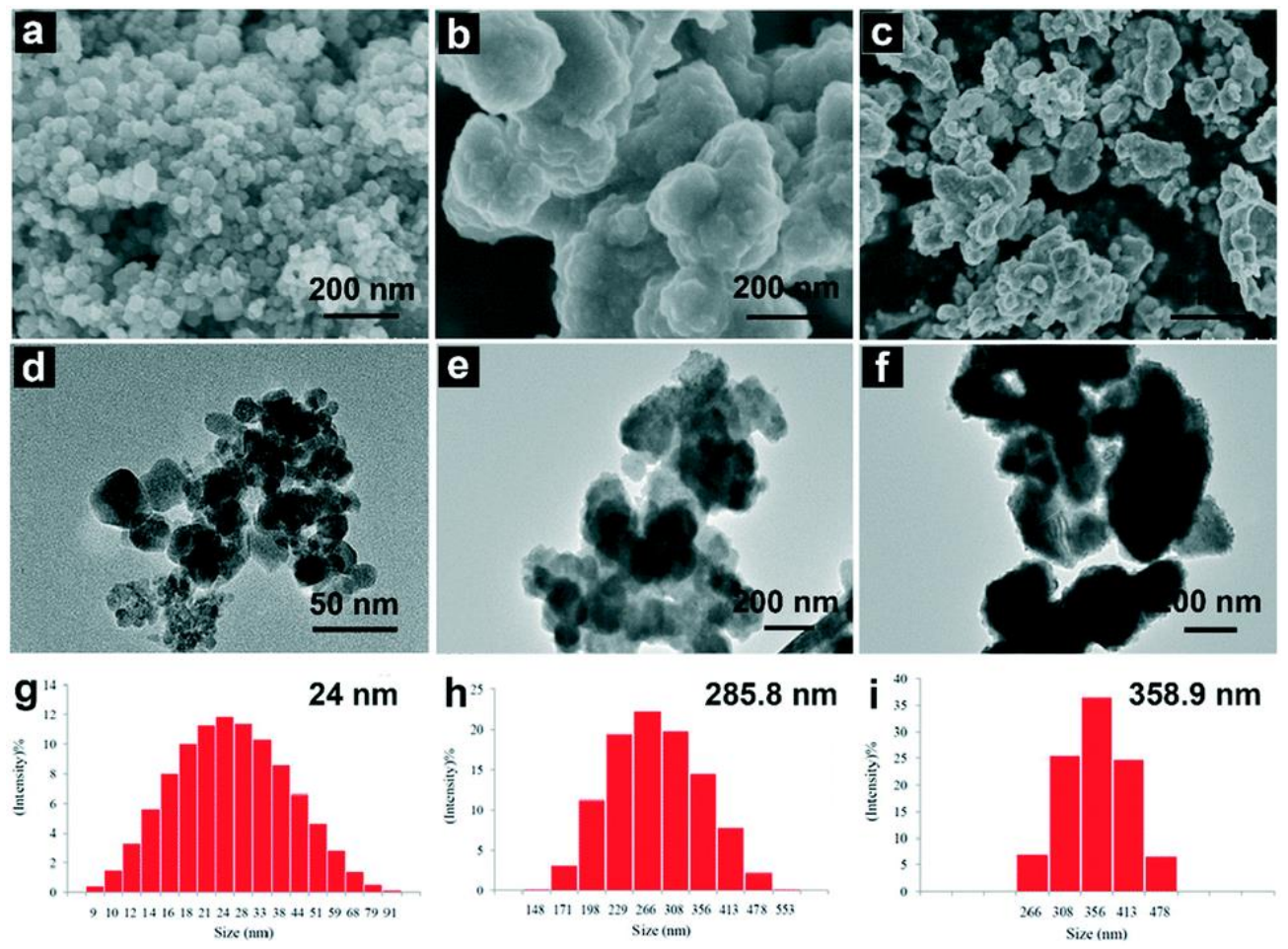

Fig. 5 SEM (a-c) and TEM (d-f) micrographs and size distribution of Cu particles prepared using different precursors at $300^{\circ} \mathrm{C}$ and $14 \mathrm{MPa}$ in methanol: (a, $d$ and $g) \mathrm{CuO},(b, e$ and $h) \mathrm{Cu}(\mathrm{NO}) 2$ and (c, f, and i) CuSO4. Reprinted with permission from ref. 102. Copyright 2014 American Chemical Society.

\section{Non-reductive supercritical solvents}

\section{Water}

Near-/supercritical $\mathrm{H}_{2} \mathrm{O}$ is one of the most investigated fluids for the synthesis of multiple types of nanomaterials, ranging from oxides, $53,140-144$ minerals, layered double hydroxides, $57,58,145,146$ sulphides, 147 to metalorganic frameworks. ${ }^{148} \mathrm{H}_{2} \mathrm{O}$ is readily available, and especially by combining it with the flow chemistry process a high-throughput scalable way of synthesis is obtained, the so-called supercritical hydrothermal flow synthesis. It is regarded as one of the key technologies towards sustainable green chemistry in the future. For the readers' reference, here are some literature studies on the process with respect to its fundamentals, ${ }^{149}$ state-of-the-art progress ${ }^{41,54,55,150}$ environmental impacts, ${ }^{151-154}$ and endeavours in upscaling. ${ }^{56,155,156}$

Among others, the interest in using supercritical $\mathrm{H}_{2} \mathrm{O}$ has also been extended to the controlled synthesis of monodispersed metal nanomaterials that are studied in both a conventional hydrothermal autoclave and flow environments. However, $\mathrm{H}_{2} \mathrm{O}$ cannot act as a reducing agent and thus the participation of additional reducing agents is indispensable. In this regard, several types of reductants have been studied including formic acid/ formate anion, ${ }^{103,108,109,112-114,157}$ polyvinylpyrrolidone (PVP), ${ }^{96,158,159}$ 1-hexanethiol, ${ }^{104}$ formaldehyde, ${ }^{105}$ hydrazine, ${ }^{110,160}$ glucose, ${ }^{116}$ and glycerol. ${ }^{97}$

Formic acid is convenient to use as it is in liquid form and totally miscible with $\mathrm{H}_{2} \mathrm{O}$ under ambient conditions, and its thermal decomposition in an aqueous environment yields mostly $\mathrm{CO}_{2}$ and $\mathrm{H}_{2} \cdot{ }^{161}$ Meanwhile, due to the significantly reduced dielectric constant of $\mathrm{H}_{2} \mathrm{O}$ in its supercritical state, supercritical $\mathrm{H}_{2} \mathrm{O}$ can dissolve non-polar compounds and gases (e.g. $\mathrm{H}_{2}$ and hydrocarbons), ${ }_{12}^{42}$ which helps in forming a homogeneous reducing environment favourable for the synthesis of metals.

Two pathways of crystallization of metals from metal cations from water-soluble precursors have been pointed 
out (Co as an example in Fig. 6a), namely hydrolysis of cations resulting in oxides/hydroxides followed by reduction of oxides/hydroxides to metals (path A) and a direct reduction of cations to metals (path B). ${ }^{103,105,108,109,112,113}$ In both cases, however, the reduction process is highly dependent on the activity of $\mathrm{H}_{2}$, and hereby the phase purity of the synthesized metals is determined. For instance, pure $\mathrm{Cu}$ was only achieved when a sufficient amount of formic acid providing $\mathrm{H}_{2}$ was introduced to the reaction, where the molar ratio between formic acid and copper formate at $5 / 1$ and above was necessary to avoid the secondary phases such as $\mathrm{CuO}$ and $\mathrm{Cu}_{2} \mathrm{O}$ in products. ${ }^{103} \mathrm{~A}$ similar observation was reported in the synthesis of $\mathrm{Co}$, in which pure Co was only obtained when the molar ratio between formic acid and cobalt acetate was above $4 / 1 .{ }^{112}$

Since the decomposition of formic acid is thermally activated, the reaction temperature also plays an important role in the phase purity of the final metal products. For example, even with a decent amount of formic acid, a reaction temperature higher than $350{ }^{\circ} \mathrm{C}$ was necessary to obtain pure $\mathrm{Cu} .{ }^{103}$

Similar results were reported with the use of other reductants on the effect of the amount of reductants on the phase purity of metal products, such as reductive synthesis in supercritical $\mathrm{H}_{2} \mathrm{O}$ of pure $\mathrm{Cu}$ by formaldehyde (min. molar ratio between formaldehyde and copper sulphate is $3 / 1)^{105}$ and of pure $\mathrm{Cu}$ and $\mathrm{Ni}$ by glycerol (min. molar ratios between glycerol and metal nitrates are $5 / 1$ and $15 / 1$, respectively). In general, the minimum amount of reductants required for obtaining pure neutral metals by reductive supercritical hydrothermal synthesis varies from metal to metal; however, it is inversely related to the reductivity of metals (Table 3). ${ }^{97,114}$

Table 3 Standard potentials at $25{ }^{\circ} \mathrm{C}$. Reprinted with permission from ref. 97. Copyright 2014 Elsevier. Original data from ref. 162

\begin{tabular}{ll}
\hline Half reaction & $E^{\circ} / \mathrm{V}$ \\
\hline $\mathrm{Pt}^{2+}+2 \mathrm{e}^{-} \rightarrow \mathrm{Pt}$ & +1.188 \\
{$\left[\mathrm{AuCl}_{4}\right]^{-}+3 \mathrm{e}^{-} \rightarrow \mathrm{Au}+4 \mathrm{Cl}^{-}$} & +0.93 \\
$\mathrm{Pd}^{2+}+2 \mathrm{e}^{-} \rightarrow \mathrm{Pd}$ & +0.915 \\
$\mathrm{Ag}^{+}+\mathrm{e}^{-} \rightarrow \mathrm{Ag}$ & +0.799 \\
$\mathrm{Cu}^{2+}+2 \mathrm{e}^{-} \rightarrow \mathrm{Cu}$ & +0.34 \\
$\mathrm{Ni}^{2+}+2 \mathrm{e}^{-} \rightarrow \mathrm{Ni}$ & -0.257 \\
$\mathrm{Co}^{2+}+2 \mathrm{e}^{-} \rightarrow \mathrm{Co}$ & -0.282 \\
$\mathrm{Fe}^{2+}+2 \mathrm{e}^{-} \rightarrow \mathrm{Fe}$ & -0.44 \\
$\left(\mathrm{Fe}^{3+}+\mathrm{e}^{-} \rightarrow \mathrm{Fe}^{2+}\right)$ & $++0.771)$ \\
&
\end{tabular}

Though fairly important, rather few efforts have been reported on how the process conditions affect the metal particle properties such as size and morphology in the reductive supercritical hydrothermal synthesis. The reaction temperature was found to be the most significant parameter that alters the size of Ag NPs synthesized in supercritical $\mathrm{H}_{2} \mathrm{O}$ in continuous flow..$^{96}$ In the investigated range of temperatures $\left(380-430{ }^{\circ} \mathrm{C}\right)$, the particle size of Ag decreased from about $23 \mathrm{~nm}$ to about $14 \mathrm{~nm}$ with the increase of temperature.

In comparison, in the synthesis of metals with relatively low standard potentials (Table 3) such as $\mathrm{Cu}$ and $\mathrm{Co},{ }^{105,112}$ the corresponding oxides can easily form from the hydrolysis process and serve as intermediates (path A in Fig. $6 a)$, especially under conditions of insufficient reductants. In this regard, not only the reaction rate but also the size of product metal NPs formed through reducing the oxide intermediates is largely dependent on the size of oxides. ${ }^{112}$ It is already well known that the nucleation and growth and thus the size of oxides under hydrothermal conditions are substantially dependent on the supersaturation. ${ }^{30,163}$ Therefore, parameters affecting the solubility and thus the supersaturation will impact the size of metal particles. Such an example was presented in the reductive supercritical hydrothermal synthesis of $\mathrm{Cu}$ NPs. ${ }^{105}$ As the solubilities of copper oxides/hydroxides in aqueous solutions were altered with the addition of $\mathrm{NaOH}$, the size of $\mathrm{Cu}$ NPs was remarkably reduced from 85 $\mathrm{nm}\left(\mathrm{NaOH}\right.$-free) to $14 \mathrm{~nm}\left(\mathrm{NaOH} / \mathrm{Cu}^{2+} \mathrm{mol} / \mathrm{mol}=2 / 1\right)$. 

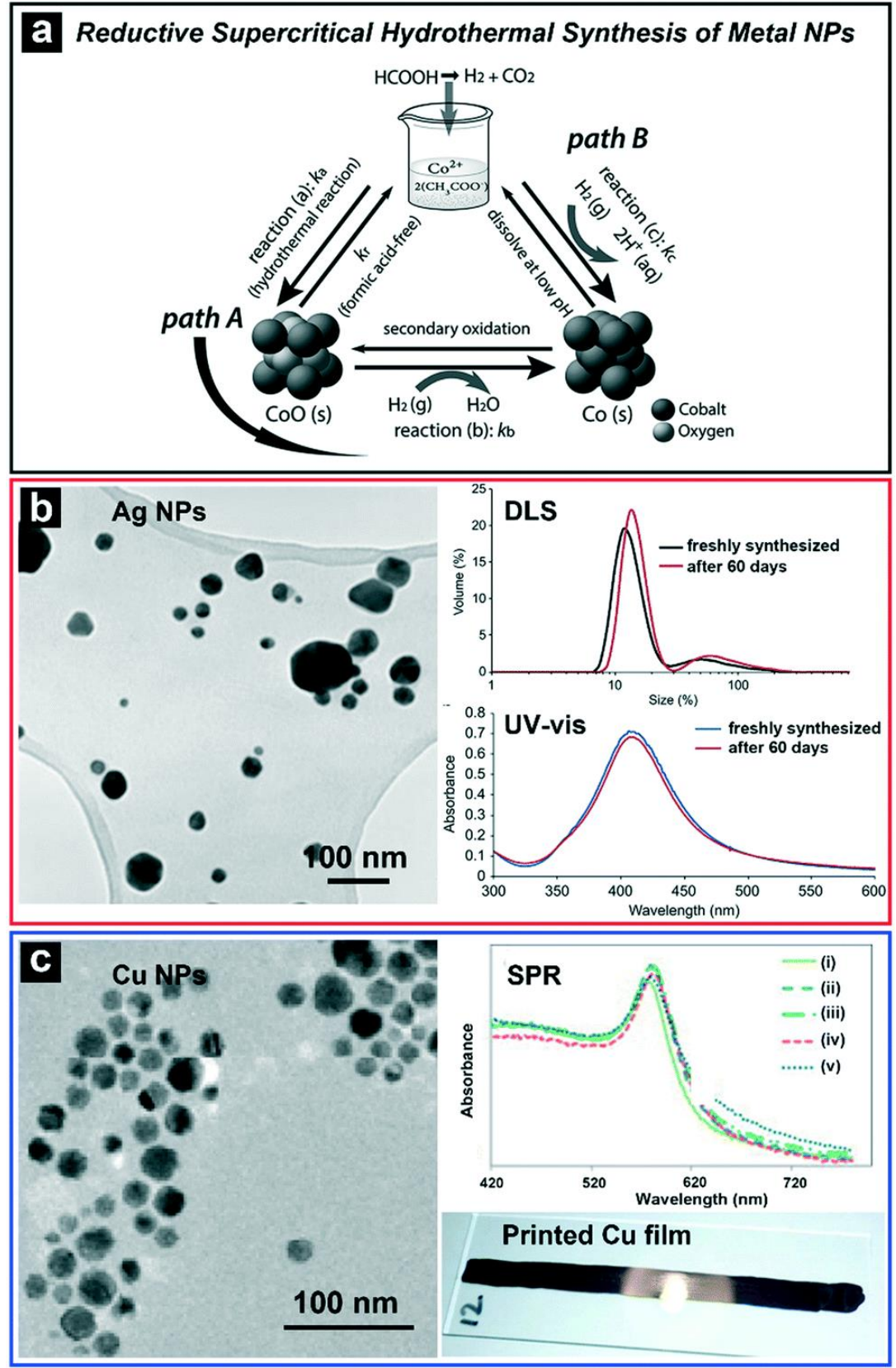

Fig. 6 (a) A scheme showing the two possible formation paths of metal NPs by reductive supercritical hydrothermal synthesis; Co NPs as an example. Reprinted with permission from ref. 112. Copyright 2014 Royal Society of Chemistry. (b) TEM micrograph of Ag NPs obtained by reductive supercritical hydrothermal synthesis in continuous flow. Dynamic light scattering (DLS) analysis of the aqueous colloids of PVP-stabilized Ag NPS as freshly synthesized and after 60 days. UV-vis absorbance spectra of the colloids displaying the same shape and the peak position indicates no change of the particle size in colloids after being stored for 60 days. Reprinted with permission from ref. 96. Copyright 2013 Elsevier. (c) TEM micrograph of Cu NPs obtained by reductive supercritical hydrothermal synthesis in continuous flow. Surface plasmon resonance (SPR) bands of PVP-stabilized Cu NP-ethanol colloids (i) as obtained and after being stored for (ii) 5 days, (iii) 15 days, (iv) 30 days and (v) 14 months show that $\mathrm{Cu}$ NPs in ethanol are stable without oxidation. A Cu film with a thickness of $0.33 \mu \mathrm{m}$ was printed by using the Cu NP-ethanol colloid. Reprinted with permission from ref. 103. Copyright 2014 Elsevier.

In general, the 'size effect' of nanomaterials originating from the high surface-to-volume ratio endows nanomaterials with extraordinary properties different from those of the bulk. ${ }^{164}$ However, it also causes an issue that nanomaterials tend to agglomerate to bring down the surface-to-volume ratio in order to make the whole system more stable. Besides agglomeration, metal NPs are also vulnerable to oxidation especially those with relatively low standard potentials. For instance, oleic acid-modified FePt and Fe NPs of $5 \mathrm{~nm}$ synthesized by the reductive supercritical hydrothermal method were extremely flammable and the whole powder exploded when it was exposed to air. ${ }^{157}$ Nevertheless, surface modification appears to be an effective way to protect the fresh assynthesized metal NPs from being oxidized by $\mathrm{H}_{2} \mathrm{O}$. Hexanoic acid was introduced to the reductive supercritical hydrothermal synthesis of Fe NPs. The synthesized Fe NPs modified by hexanoic acid and suspended in $\mathrm{H}_{2} \mathrm{O}$ did not display any phase changes after being stored in an Ar-purged glove box for 20 days, whereas those synthesized without hexanoic acid were oxidized by $\mathrm{H}_{2} \mathrm{O}$ after a few days. ${ }^{114}$ 
In addition, surface modifiers are useful in alleviating agglomeration and improving the colloidal stability of the as-synthesized metal nanoparticle suspensions, which displays advantages from both the viewpoints of production and application. For example, in the study of flow synthesis of Ag NPs by the reductive supercritical hydrothermal method, PVP (molecular weight $M_{\mathrm{w}} 50000 \mathrm{~g} \mathrm{~mol}^{-1}$ ) was helpful in preventing Ag NPs from agglomerating and sticking to the wall of the tubes which would otherwise result in clogging the flow-type setup. ${ }^{96}$ This is of a great practical significance as it will allow for increasing the particle product recovery efficiency, using precursor solutions at high concentrations, and reducing downtime. Meanwhile, an improved colloidal stability of the suspension of Ag NPs synthesized with the presence of PVP was shown by the almost identical particle size distribution measured by dynamic light scattering (DLS) with the fresh suspension and the suspension stored for 60 days (Fig. 6b). ${ }^{96}$ A similar result was obtained with the PVP-stabilised Cu NP suspension in ethanol. PVP $\left(M_{\mathrm{w}} 40000 \mathrm{~g} \mathrm{~mol}^{-1}\right)$ was introduced to the reductive supercritical hydrothermal synthesis of $\mathrm{Cu}$ and used to modify the surface of the as-synthesized NPs (Fig. 6c). The PVP-stabilized Cu NPs were well dispersed in ethanol and did not form precipitates for 14 months. In addition, such Cu NPs are not susceptible to oxidation when stored in ethanol, as proven by the unchanged peak position in the surface plasmon resonance (SPR) bands derived from Cu NPs stored after different periods of time up to 14 months. Such stable suspensions are interesting for applications like inks for printed electronics that have a high homogeneity and reduced chances of blocking printer heads. A conductive film with a thickness of $0.33 \mu \mathrm{m}$ was printed with inks made of the suspension, of which the resistivity was $16 \mu \Omega \mathrm{cm}$ (approximately 10 times that of the bulk $\mathrm{Cu}$ ). ${ }^{103}$

Organic molecules also serve as ligands to bond metal cations to form complexes as precursors, the type of which later determines the formation path of metals, as an example presented in the flow reductive hydrothermal synthesis of $\mathrm{Ni} .{ }^{108}$ 1,10-Phenanthroline (phen, $\mathrm{C}_{12} \mathrm{H}_{8} \mathrm{~N}_{2}$ ) strongly associated with $\mathrm{Ni}^{2+}$ at room temperature, which inhibits the hydrolysis of $\mathrm{Ni}^{2+}$ in aqueous solutions. However, when $\left[\mathrm{Ni}(\text { phen })_{3}\right]^{2+}$ was mixed with the preheated $\mathrm{H}_{2} \mathrm{O}$ stream, it decomposed upon rapid heating while the hydrolysis of dissociated $\mathrm{Ni}^{2+}$ was not pronounced at the investigated temperatures $\left(320-360^{\circ} \mathrm{C}\right.$ ). As a result, $\mathrm{Ni}$ was formed by directly reducing $\mathrm{Ni}^{2+}$ (path B in Fig. 6a) right after the decomposition of $\left[\mathrm{Ni}(\mathrm{phen})_{3}\right]^{2+}$. As the properties of the synthesized metal NPs are largely dependent on the formation path, 112 this can be used to optimize the synthesis conditions of metal NPs in the reductive hydrothermal process.

To summarize, as a green and readily available substance in nature, water has drawn attention for its use in the supercritical fluid technique for nanomaterial synthesis, leading to the established supercritical hydrothermal flow synthesis, in particular. Obtaining metal nanomaterials by the reductive supercritical hydrothermal synthesis has been studied in both autoclaves and flow-type apparatus. Formic acid and some other chemicals have been used as reductants in the process. Supercritical water behaves as a non-polar solvent, which forms a homogeneous reductive environment as it becomes miscible with gases (e.g. $\mathrm{H}_{2}$ from formic acid decomposition). The amount of reductants influences the phase purity of the synthesized metal nanomaterials. Increasing the temperature enhances the thermal decomposition of reductants, formic acid for instance, which impacts the phase purity as well. Besides, a decreased particle size is observed with increasing temperature. Two pathways of forming metal nanomaterials in the reductive supercritical hydrothermal synthesis have been proposed, i.e. through the hydrolysis and reduction with oxides/hydroxides as intermediates and through the direct reduction of metal cations. The nature of the metal and the reductant, the relative amounts between the reductant and the metal cations, the temperature and the ligands bonded to the cations appear to determine the path following which the metal nanomaterials are formed. During the synthesis, organic molecules can be introduced as surface modifiers to improve the stability of the aqueous metal nanomaterial suspensions. Firstly, they can protect the active metal nanoparticles from being oxidized by water. Secondly, they help prevent the metal nanomaterials from agglomerating, which is advantageous to both a smooth synthesis process and an easy transfer of suspensions to downstream applications.

\section{Carbon dioxide}

For a long time, supercritical $\mathrm{CO}_{2}$ has been noticed as one of the promising alternatives to organic solvents to achieve the so-called green chemical and industrial processes with easy solvent separation and recyclability. ${ }^{165,166}$ Among others, two fundamental reasons drive such an attraction: (1) relatively mild conditions $\left(31^{\circ} \mathrm{C}, 7.38 \mathrm{MPa}\right)$ are needed to reach the supercritical conditions with $\mathrm{CO}_{2}$ (Table 1), and (2) it exhibits distinct physicochemical properties including a liquid-like density $\left(0.1-1 \mathrm{~g} \mathrm{~cm}^{-3}\right)$, gas-like viscosity $\left(10^{-4}-10^{-3} \mathrm{~g} \mathrm{~cm}^{-1} \mathrm{~s}^{-1}\right)$, zero surface tension and so on. Moreover, supercritical $\mathrm{CO}_{2}$ itself as a non-polar solvent can solubilize hydrogen, chelate complexes and metal-organic compounds. It is also completely miscible with some organic compounds such as methanol, ethanol, toluene, acetone, formic acid and acetic acid which are typical solvents with a broad range of 
uses. ${ }^{167}$ Another notable advantage of using supercritical $\mathrm{CO}_{2}$ compared with using liquid solvents is that it can easily penetrate porous structures, even the mesoporous ones, thanks to its zero surface tension and high diffusivity. These properties add up and make supercritical $\mathrm{CO}_{2}$ an ideal carrier and indeed it has been widely applied in material processing and synthesis.

The versatility of using supercritical $\mathrm{CO}_{2}$ in the development of metal nanomaterials has been shown in various forms, including (1) the synthesis and $\mathrm{CO}_{2}$-assisted synthesis of monodispersed metal NPs, in both the bottomup ${ }^{51,87-89,91,98-101,107,118}$ and top-down ${ }^{119,120}$ ways, (2) micelles dispersed in supercritical $\mathrm{CO}_{2}$ as 'nano-reactors' for the growth of metal NPs, ${ }^{168-178}$ (3) template growth of robust metal nanostructures (nanofilms, ${ }^{60,62,179-191}$ nanowires, nanotubes ${ }^{192-195}$ and porous nanostructures ${ }^{196-198}$ ), and (4) deposition and immobilization of metal NPs on porous supports that emerged as composites. ${ }^{61,81-84,199-214}$ Here, the review focuses only on the first two applications that will be discussed in the following paragraphs, while the last two in relation to the use of supercritical $\mathrm{CO}_{2}$ in template growth and deposition are out of scope. Nevertheless, research studies on the template growth of 2D/3D metal nanostructures and the fabrication of the supported metal NP composites, known as supercritical fluid reactive/chemical deposition (SFRD/SFCD), have rapidly increased in recent years. These metal nanostructures and composites display extraordinary performances in catalysis. Massive efforts have been made and readers interested in the advancements in the field may find comprehensive reviews and selected examples. ${ }^{61,81-84,199-214}$

Supercritical $\mathrm{CO}_{2}$ can enhance the solubility of $\mathrm{H}_{2}$ in toluene ${ }^{215}$ to create a homogeneous reductive environment favourable for the reductive synthesis of metal NPs. ${ }^{51,87}$ As an example, Pd NPs (2-4 nm) were prepared in toluene flows by hydrogen reduction of $\mathrm{Pd}(\mathrm{ii})$ bis(hexafluoroacetylacetonate) and their surfaces were in situ bonded to different functional ligands solubilized in toluene and introduced during the synthesis. Further, these Pd NPs were studied as catalysts for the borylation reaction and the performance was dependent on the stereoelectronic properties of Pd NPs regulated by the ligands.
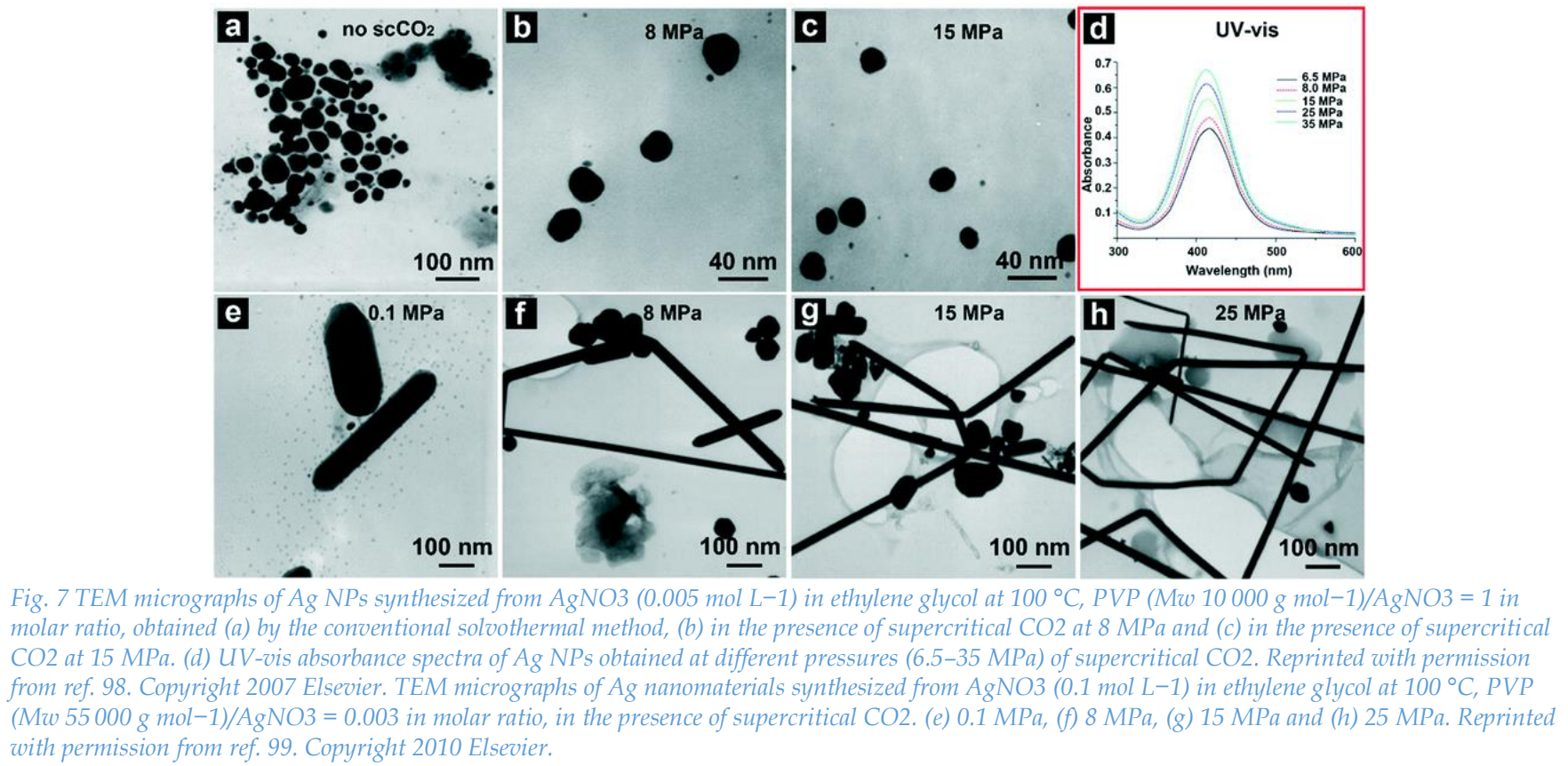

In addition, it was found that the participation of supercritical $\mathrm{CO}_{2}$ in the solvothermal synthesis of metal nanomaterials is able to alter the properties of metal products (Fig. 7). ${ }^{98,99} \mathrm{Ag}$ NPs obtained by the solvothermal synthesis from $\mathrm{AgNO}_{3}$ in ethylene glycol displayed a smaller and more uniform size distribution when supercritical $\mathrm{CO}_{2}\left(100^{\circ} \mathrm{C}, 25 \mathrm{MPa}\right)$ was introduced to the synthesis (Fig. $7 \mathrm{~b}$ and c), in comparison with those synthesized in the absence of supercritical $\mathrm{CO}_{2}$ (Fig. 7a). This is mainly because the introduction of supercritical $\mathrm{CO}_{2}$ decreased the viscosity but increased the fluidity and diffusivity of ethylene glycol which enhanced the mass diffusion and promoted the reaction and nucleation rates. Such an effect was further analysed by varying the pressure, a controlling parameter to the density-related properties of supercritical $\mathrm{CO}_{2}$. Increasing the pressure promoted the mass transfer, and smaller Ag NPs were obtained at higher pressures (Fig. $7 \mathrm{~b}$ and c). This was identified by UV-vis analysis of Ag NPs obtained at different pressures (Fig. 7d). The bands in the absorbance spectra shifted to lower wavelengths with a steadily increasing intensity as pressure increased, indicating that smaller but increased amounts of particles were obtained at higher pressures. ${ }^{98}$ The morphology of Ag 
nanomaterials was affected by the pressure as well. Increased amounts of nanowires were obtained in the products by increasing the pressure of supercritical $\mathrm{CO}_{2}$, while the diameter of the nanowires decreased, resulting in an increased length/diameter aspect ratio (Fig. 7e-h). ${ }^{99}$

As mentioned earlier, supercritical $\mathrm{CO}_{2}$ itself is able to dissolve metal-organic compounds that are used as precursors for the synthesis of metal nanomaterials. Indeed, supercritical $\mathrm{CO}_{2}$ has been applied as the single reaction medium for metal reductive synthesis, mostly noble metals. To this end, typical $\mathrm{CO}_{2}$-soluble metalorganic compounds both commercially available and laboratory-customized that have been adopted in previous studies include dimethyl(1,5-cyclopentadiene) $\mathrm{Pt}(\mathrm{ii}){ }^{91}$ triphenylphosphine $\mathrm{Au}(\mathrm{i})$ perfluorooctanoate, ${ }^{118} \mathrm{Pd}(\mathrm{ii})$ bis(acetate), ${ }^{88} \mathrm{Pd}(\mathrm{ii})$ bis(hexafluoroacetylacetonate), ${ }^{89}$ methylcyclopentadienyl (1,5-cyclooctadiene) $\operatorname{Ir}(\mathrm{i}),{ }^{91} \mathrm{Ag}(\mathrm{i})$ acetylacetonate, $88,91,100 \mathrm{Ag}$ (i) bis(3,5,5-trimethyl-1-hexyl) sulfosuccinate ${ }^{101}$ and $\mathrm{Ag}$ (i) (1,1,1,5,5,5-hexafluoropentane2,4-dione) tetraglyme. ${ }^{89}$ Either $\mathrm{H}_{2}{ }^{89,91,100}$ or reductants dissolved in ethanol such as dimethylamine borane ${ }^{88,118}$ and sodium borohydride ${ }^{101}$ are typically used for the reduction process, given that supercritical $\mathrm{CO}_{2}$ has a high miscibility with $\mathrm{H}_{2}$ and ethanol which facilitates a homogeneous reductive environment. The fluorinated surfactants ${ }^{216}$ are usually added to the reductive synthesis process in order to passivate particle growth and agglomeration, such as the perfluorooctane thiol $(1 \mathrm{H}, 1 \mathrm{H}, 2 \mathrm{H}, 2 \mathrm{H}$-perfluorooctanethiol $)$ and the surfactant with perfluoropolyether chains, $\left[\mathrm{CF}_{3} \mathrm{O}\left(\mathrm{CF}_{2} \mathrm{CFCF}_{3} \mathrm{O}\right)_{m}-\left(\mathrm{CF}_{2} \mathrm{O}\right)_{n} \mathrm{CF}_{2} \mathrm{CH}_{2}-\left(\mathrm{OCH}_{2} \mathrm{CH}_{2}\right)_{p} \mathrm{OPO}_{3}\right]_{2} \mathrm{NH}\left(\mathrm{CH}_{2}-\mathrm{CH}_{2} \mathrm{OH}\right)_{2}$.

The concentration of precursors indeed has an effect on the properties of metal NPs. For instance, the average size of Ag NPs synthesized by reducing Ag acetylacetonate in supercritical $\mathrm{CO}_{2}\left(60-100^{\circ} \mathrm{C}, 27.6 \mathrm{MPa}\right)$ increased (2.6$10.7 \mathrm{~nm})$ with the concentration of dissolved $\mathrm{Ag}$ acetylacetonate $\left(1.8-4.9 \mathrm{mmol} \mathrm{L}{ }^{-1}\right) .{ }^{91}$ However, it seems that this observation does not apply to the condition with a rather dilute solution of the precursor in supercritical $\mathrm{CO}_{2}$. The particle size of $\mathrm{Au}(1.0-1.1 \mathrm{~nm})$ was independent of the concentration $\left(0.1-0.3 \mathrm{mmol} \mathrm{L}^{-1}\right)$ of triphenylphosphine $\mathrm{Au}$ (i) perfluorooctanoate (TPAuFO) in supercritical $\mathrm{CO}_{2}\left(40^{\circ} \mathrm{C}, 16 \mathrm{MPa}\right)$. The yield and population of $\mathrm{Au} N \mathrm{NP}$ instead increased with the concentration of TPAuFO, identified by the proportionally increased intensity of the UV-vis absorption peak corresponding to Au NPs. ${ }^{118}$

The pressure, which alters the density and thus the solvent power of supercritical $\mathrm{CO}_{2}$, also largely affects the particle properties. Such an example was presented in the synthesis of Ag NPs through reducing Ag acetylacetonate in supercritical $\mathrm{CO}_{2}\left(80{ }^{\circ} \mathrm{C}, 20.7-34.5 \mathrm{MPa}\right)$ at various pressures. ${ }^{100}$ The particle size was independent of the pressure and was kept constant at around $2 \mathrm{~nm}$ when the pressure was higher than $27.6 \mathrm{MPa}$. In comparison, the particle size decreased from $4.0 \mathrm{~nm}$ to $1.7 \mathrm{~nm}$ with increasing pressure from $20.7 \mathrm{MPa}$ to 27.6 $\mathrm{MPa}$. This was due to the dissolution of the fluorinated thiol surfactant in supercritical $\mathrm{CO}_{2}$ being enhanced with the increase of the density by increasing the pressure. More dissolved ligands adsorbed on the Ag NPs were helpful in reducing the collision and coagulation among Ag NPs which was identified as the main mechanism for particle growth in metal-supercritical $\mathrm{CO}_{2}$ colloids.

Supercritical $\mathrm{CO}_{2}$ itself as a non-polar solvent has been applied alternatively as the continuous phase in microemulsions for aqueous reverse micelles, in order to address issues such as the separation and removal of solvents from products in relation to the use of water-in-oil microemulsions for the synthesis of nanomaterials. ${ }^{168,169}$ As such, the aqueous micelles provide accommodation to the chemical reaction and the size of the formed nanocrystals is highly dependent on the size of micelles which is typically $5-25 \mathrm{~nm} .{ }^{168}$

Typically, surfactants are necessary for the formation and good dispersion of micelles to ensure a stable microemulsion. Herein the surfactants are usually amphiphilic with a hydrophilic head and the other oil/ $\mathrm{CO}_{2}-$ philic.168,171 Surfactants such as sodium bis(2-ethylhexyl) sulfosuccinate (AOT) often used in water-in-oil microemulsions are not suitable for water-in-supercritical $\mathrm{CO}_{2}$ microemulsions due to their poor solubilities in supercritical $\mathrm{CO}_{2}$. Alternative surfactants, mostly the fluorinated ones with improved solubilities in $\mathrm{CO}_{2}$, are thus developed and used as surfactants or co-surfactants, including ammonium carboxylate perfluoropolyether (PFPE) ${ }^{172,173}$ co-surfactants with AOT such as 2,2,3,3,4,4,5,5-octafluoro-1-pentanol ${ }^{169}$ and PFPE-phosphate, ${ }^{174,175}$ and recently reported metal complexes, e.g. Fe tris(2,2,6,6-tetramethyl-3,5-heptanedionato).217

Readers may notice in the previous parts that precursors for the reductive synthesis of metal nanomaterials in supercritical $\mathrm{CO}_{2}$ are restricted to metal-organic compounds due to their good solubilities in supercritical $\mathrm{CO}_{2}$. Using water-in-supercritical $\mathrm{CO}_{2}$ microemulsions with aqueous cores however enriches the choice of metal precursors available for the reductive synthesis of metal NPs in supercritical $\mathrm{CO}_{2}$, since inorganic precursors soluble in water but insoluble in supercritical $\mathrm{CO}_{2}$ can be used, as shown in the synthesis of $\mathrm{Pt}, \mathrm{Pd}, \mathrm{Ag}$ and $\mathrm{Cu}$ 
NPs. ${ }^{168-178}$ For instance, Pd NPs of 5-10 nm were prepared by the method of water-in-supercritical $\mathrm{CO}_{2}$ microemulsions from aqueous $\mathrm{Pd}^{2+}$ reduced by $\mathrm{H}_{2}$ in supercritical $\mathrm{CO}_{2}\left(50{ }^{\circ} \mathrm{C}, 20 \mathrm{MPa}\right) .175$

The water-to-surfactant molar ratio $W$ that controls the size of aqueous cores (micelles) in a proportional way ${ }^{168}$ can be used to control the size of metal NPs since the nucleation and growth occur within the cores. Such an example is presented in the $\mathrm{H}_{2}$ reductive synthesis of $\mathrm{Ag} \mathrm{NPs}$ through microemulsions of aqueous $\mathrm{Ag}^{+}$cores dispersed in a mixture of toluene $(20 \mathrm{vol} \%)$ and supercritical $\mathrm{CO}_{2}\left(40^{\circ} \mathrm{C}, 18.5 \mathrm{MPa}\right)$ (Fig. 8a). ${ }^{176}$ As $W$ was gradually increased from 4, 6, 8 to 10, the size of Ag NPs became increasingly larger and was $2.5 \mathrm{~nm}, 4.1 \mathrm{~nm}, 5.3$ $\mathrm{nm}$ and $6.3 \mathrm{~nm}$, respectively (Fig. 8b). A notable observation is that the size of Ag NPs followed a linear dependence on the density of supercritical $\mathrm{CO}_{2}$ in the method of water-in- $\mathrm{CO}_{2}$ microemulsion synthesis. ${ }^{177}$ Increasing the density of supercritical $\mathrm{CO}_{2}\left(32-65^{\circ} \mathrm{C}, 28-46 \mathrm{MPa}\right)$ either by decreasing the temperature or increasing the pressure resulted in smaller Ag NPs (3-9 nm) (Fig. 8c and d).

a
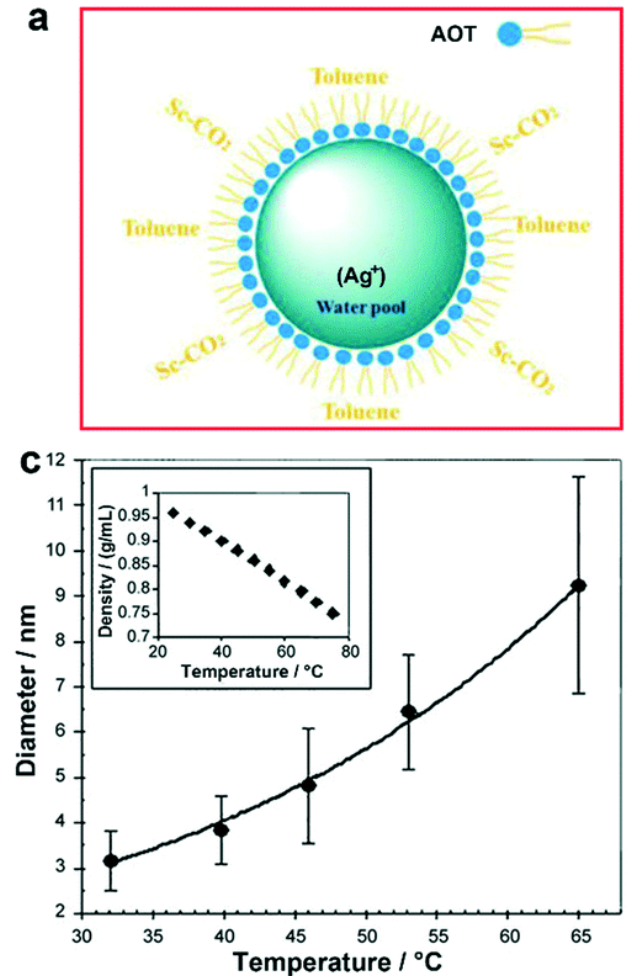

b
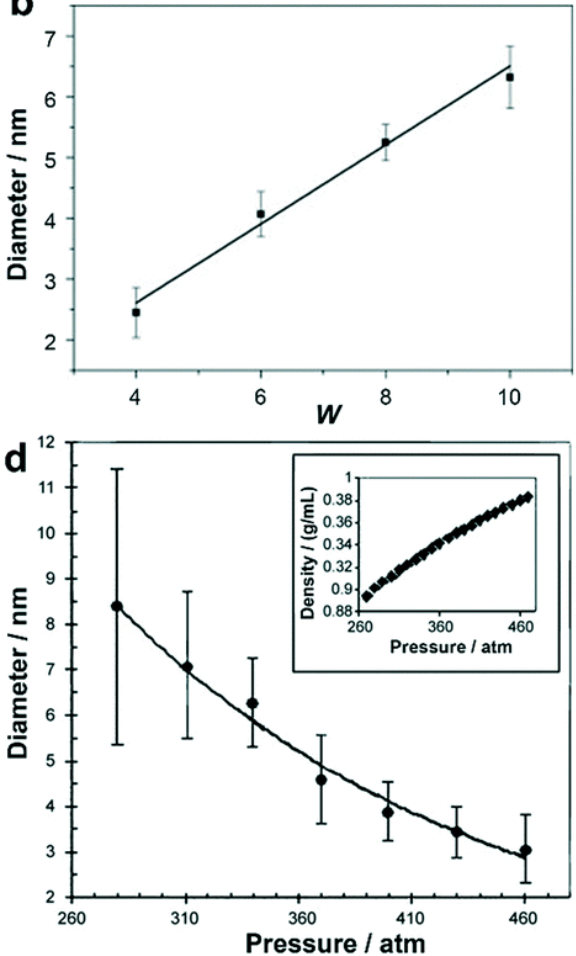

Fig. 8 (a) A schematic of water-in-(toluene and supercritical CO2) microemulsions composed of aqueous Ag+ cores dispersed in a mixture of toluene and supercritical CO2. AOT is used as the surfactant. (b) The linear relation between the diameter of Ag NPs and the molar ratio of water to surfactant (W) in the water-in-(toluene and supercritical CO2) microemulsions. Reprinted with permission from ref. 176 . Copyright 2015 Elsevier. (c) Influence of temperature on the average size and size distribution of Ag nanoparticles at a fixed CO2 pressure of $280 \mathrm{~atm}, \mathrm{~W}=6$, surfactant [F-AOT] $10 \mathrm{mmol} L-1$. Inset: Density versus temperature at a fixed pressure of $280 \mathrm{~atm}$. (d) Influence of CO2 pressure on the average size and size distribution of Ag nanoparticles at $40^{\circ} \mathrm{C}, W=6$, surfactant [F-AOT] $20 \mathrm{mmol} \mathrm{L-1}$. Inset: Density versus pressure at a fixed temperature of $40^{\circ} \mathrm{C}$. Reprinted with permission from ref. 177. Copyright 2006 J. Wiley.

In this section, the applications of supercritical $\mathrm{CO}_{2}$ in the synthesis of metal nanomaterials are reviewed. Attention is paid to its roles as a co-solvent and a single solvent in chemical reductive solvothermal synthesis of metal nanomaterials and as a replacement for the conventional solvents in microemulsion synthesis. Supercritical $\mathrm{CO}_{2}$, miscible with gases (e.g. $\left.\mathrm{H}_{2}\right)$ and organic solvents (e.g. toluene) at the same time, can be used to enhance the solubility of $\mathrm{H}_{2}$ in toluene which benefits the formation of a homogeneous reductive environment for the synthesis of metal nanomaterials. The introduction of supercritical $\mathrm{CO}_{2}$ to the solvothermal synthesis results in metal nanoparticles with a decreased and more monodispersed size, mainly due to the enhanced mass diffusion. The density of supercritical $\mathrm{CO}_{2}$, which can be substantially altered via the pressure, affects its solvent power. Accordingly, effects on the properties of the synthesized metal nanomaterials are considered as a result of interactions between the dissolved precursors, reductants, surfactants and metal nanomaterials. Importantly, supercritical $\mathrm{CO}_{2}$ can be easily separated and recovered after the synthesis, in line with the demands of green chemical and industrial processes. To the same end, supercritical $\mathrm{CO}_{2}$ has been used to form water-in- $\mathrm{scCO}_{2}$ (supercritical $\mathrm{CO}_{2}$ ) microemulsions for metal nanoparticle synthesis, as an alternative to the typically used organic-solvent-based continuous phase in water-in-oil microemulsions. 


\section{Mechanism of the formation of metal nanostructures in supercritical fluids revealed by in situ techniques}

Similar to the cases in other synthetic methods, there is growing interest in monitoring and following the crystallization and growth of metal nanomaterials in supercritical fluids in real time by in situ techniques. As such, collected information can be used to light up the 'black box' and later to efficiently optimize the synthesis conditions for the customized product materials.

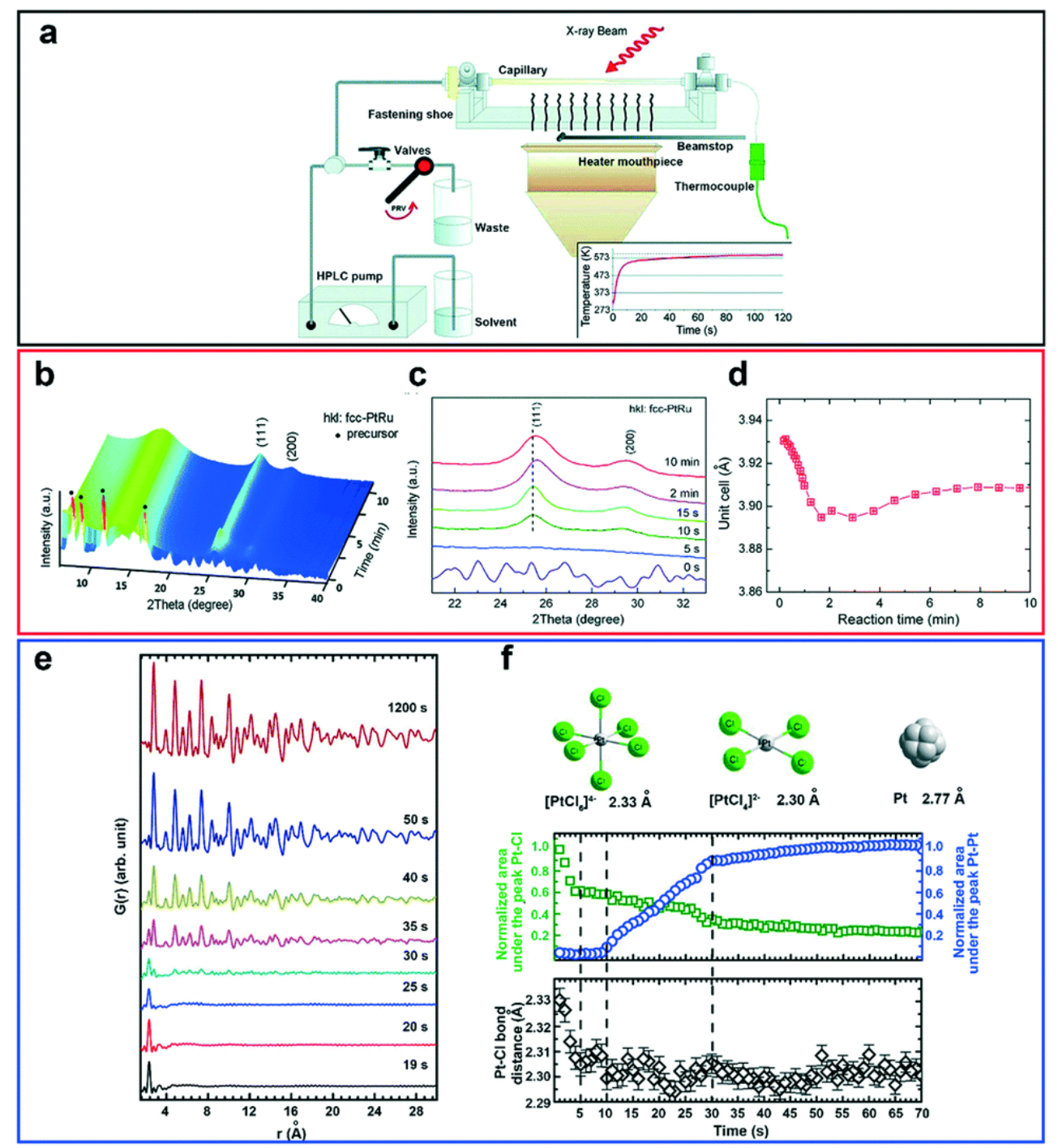

Fig. 9 (a) A scheme of an in situ setup working with (synchrotron) X-ray radiation developed by B. Iversen's group. Reprinted with permission from ref. 220. Copyright 2010 International Union of Crystallography. (b)-(d) In situ X-ray diffraction analysis of the synthesis process of PtRu alloy NPs in ethanol: (b) time-resolved XRD patterns, (c) XRD patterns at some selected times, the dashed line marks the peak position for the (111) planes of the primary NPs, and (d) time-resolved lattice parameters derived from in situ diffraction patterns. Reprinted with permission from ref. 242. Copyright 2015 Royal Society of Chemistry. (e) and (f) In situ X-ray total scattering coupled with PDF analysis of the synthesis process of Pt NPs in supercritical ethanol: (e) time-resolved PDF derived from the scattering data, and (f) time evolution of the normalized area under the PDF peaks for Pt-Cl and Pt-Pt bonds (top) and time evolution of changes in the Pt-Cl bond distance (bottom). Reprinted with permission from ref. 243. Copyright 2015 American Chemical Society.

Thanks to its high energy and good transmission capabilities, (synchrotron) X-rays are used widely as the radiation source in most of the developed in situ techniques, such as small/wide-angle X-ray scattering/total scattering, tomography and energy-dispersive diffraction imaging. The presence of supercritical fluids, however, complicates the design of in situ setups since the high-pressure and high-temperature environment should be taken into consideration. Nevertheless, several designs have been successfully built by a number of groups 69,218-225 which allow in situ studies in both the batch and the flow status (e.g.Fig. 9a). ${ }^{220}$ Noting the popular interest in the use of water, numerous results have been obtained with synthesis of simple and complex oxides under hydrothermal conditions working with near- or supercritical water, which helps to understand the nucleation and growth and the evolution of phases, crystallite size and macrostrain. ${ }^{226-236}$ Other in situ techniques based on 
Raman spectroscopy, infrared radiation and visible light ${ }^{237-240}$ have also been developed to study the physicochemical processes in supercritical fluids.

These methods and setups in practice can be transferred to the studies on the synthesis of metal nanomaterials in other supercritical fluids, given that $\mathrm{H}_{2} \mathrm{O}$ has rather harsh supercritical conditions in comparison with the others. For instance, in situ X-ray diffraction by using a synchrotron radiation source was shown to be powerful in following the crystallization of Ru and Pt NPs in (sub-)supercritical ethanol and studying the effects of the type of precursor and temperature. ${ }^{90,241}$ Diffraction peaks corresponding to face-centred-cubic $\mathrm{Ru}$ (fcc Ru) appeared $90 \mathrm{~s}$ after heating when Ru tris(acetylacetonate) was used as the precursor dissolved in ethanol $\left(200{ }^{\circ} \mathrm{C}, 25 \mathrm{MPa}\right)$. In contrast, hexagonal-close-packed $\mathrm{Ru}$ (hcp Ru) started to nucleate only $10 \mathrm{~s}$ after heating when applying identical conditions but with $\mathrm{RuCl}_{3}$ as the precursor. In the former, fcc Ru was obtained by the direct reduction of $\mathrm{Ru}$ tris(acetylacetonate) and its crystallite size remained unchanged $180 \mathrm{~s}$ after heating. Instead, the diffraction peak intensity continued to increase in $960 \mathrm{~s}$, suggesting that the nucleation of fresh crystals overweighed the crystal growth. Prior to the nucleation of hcp Ru from $\mathrm{RuCl}_{3}$, however, an intermediate crystalline phase was identified and it steadily disappeared along with the nucleation of hcp Ru. This indicates that hcp Ru was not formed by directly reducing $\mathrm{RuCl}_{3}{ }^{90}$ In addition, the dependence of the reduction and nucleation rate on the temperature was illustrated straightforwardly by in situ X-ray diffraction. Only after $10 \mathrm{~s}$, diffraction peaks corresponding to crystalline $\mathrm{Ru}$ were identified when the temperature of the reaction between $\mathrm{Ru}$ tris(acetylacetonate) and ethanol was increased to $400{ }^{\circ} \mathrm{C}$, compared with $90 \mathrm{~s}$ at $200^{\circ} \mathrm{C} .9^{0}$ Similar results were observed in the reductive synthesis of $\mathrm{Pt} \mathrm{NPs}$ from $\mathrm{H}_{2} \mathrm{PtCl}_{6}$ in ethanol. At a low temperature $\left(200^{\circ} \mathrm{C}, 25 \mathrm{MPa}\right), \mathrm{Pt}$ crystallites started to be identified $120 \mathrm{~s}$ after heating, and this period was remarkably reduced to just a few seconds when the temperature was increased to $250^{\circ} \mathrm{C}$ and above. ${ }^{241}$

In situ X-ray diffraction helps in figuring out the formation path of alloy NPs in (sub-)supercritical fluids which is contradictory to the mechanism based on the assumption of the simultaneous co-reduction of metal precursors, as an example presented in the synthesis of $\mathrm{Bi}_{2} \mathrm{Te}_{3} \mathrm{NPs}$. During the first $90 \mathrm{~s}$ in the synthesis of $\mathrm{Bi}_{2} \mathrm{Te}_{3} \mathrm{NPs}_{\mathrm{s}}$ subcritical $\mathrm{H}_{2} \mathrm{O}\left(250-300{ }^{\circ} \mathrm{C}, 25 \mathrm{MPa}\right)$ with $\mathrm{BiCl}_{3}$ and $\mathrm{Te}(\mathrm{OH})_{6}$ as precursors, $\mathrm{BiOCl}$ and Te were identified, resulting from the hydrolysis of $\mathrm{BiCl}_{3}$ in $\mathrm{H}_{2} \mathrm{O}$ and the reduction of $\mathrm{Te}(\mathrm{OH})_{6}$ by alginic acid, respectively. Later $\mathrm{Bi}_{2} \mathrm{Te}_{3}$ crystals started to appear $240 \mathrm{~s}$ after initiating the reaction, whereas Te crystals steadily diminished. Phasepure $\mathrm{Bi}_{2} \mathrm{Te}_{3}$ was obtained in $810 \mathrm{~s}$ while throughout the process no crystalline metallic Bi phase was detected. ${ }^{117}$ Another example exists describing the formation path of PtRu alloy NPs in subcritical ethanol $\left(200^{\circ} \mathrm{C}, 25 \mathrm{MPa}\right)$ which was also revealed by the data collected by in situ X-ray diffraction during the process (Fig. 9b). Diffraction peaks corresponding to face-centered-cubic $\mathrm{Pt}(\mathrm{fcc} \mathrm{Pt}$ ) were identified $10 \mathrm{~s}$ after heating the precursor solutions composed of Pt bis(acetylacetonate) and Ru bis(acetylacetonate) in ethanol. Afterwards, especially after $120 \mathrm{~s}$, the peak positions started to shift to higher diffraction angles, indicating the contraction of lattice parameters which became more and more close to those of PtRu (Fig. 9c and d). Meanwhile, the crystallite size derived from the peak broadening showed that in the first $10-15 \mathrm{~s}$, it peaked at $4.9 \mathrm{~nm}$ but later it decreased to about $3 \mathrm{~nm}$, an equilibrium size after $120 \mathrm{~s}$. Note that the variation came together with the peak shifting and the latter indicates the formation of PtRu. Herein, crystallization of Ru on surfaces of the pre-formed Pt NPs and diffusion of Ru into $\mathrm{Pt}$, resulting in further disorder in the bimetallic crystal structure, were supposed to cause the decrease of the crystallite size. ${ }^{242}$

The limitation of the in situ diffraction technique nevertheless is quite clear that it can only reveal the evolution of crystalline phases. Total X-ray scattering, also known as pair distribution function (PDF) analysis, complements the issue and is able to characterize structures that are intrinsically disordered so as to provide valuable information on the process prior to the crystallization. ${ }^{220,229,230,243,244}$

For instance, by calculating the atomic pair distance distribution from the in situ X-ray total scattering data, peaks in the temporally evolved distributions assigned to the $\mathrm{Pt}-\mathrm{Cl}$ and $\mathrm{Pt}-\mathrm{Pt}$ bonds were used to clarify the transformation process in the primary stage during the synthesis of $\mathrm{Pt} \mathrm{NPs}$ by reducing $\mathrm{H}_{2} \mathrm{PtCl}_{6}$ in supercritical ethanol $\left(250^{\circ} \mathrm{C}, 25 \mathrm{MPa}\right)$ (Fig. 9e). ${ }^{243}$ Initially, the identified peak at $2.33 \AA$ indicates the presence of $\mathrm{Pt}^{4+}-\mathrm{Cl}$ in the octahedral $\left[\mathrm{PtCl}_{6}\right]^{2-}$ complexes after the dissolution of the precursor in ethanol. In the first $5 \mathrm{~s}$, the integrated area under the peak $(2.33 \AA)$ rapidly decreased and reached a plateau because of the breakage of the bond. At the same period, the bond distance decreased to $2.30 \AA$ which corresponds to $\mathrm{Pt}^{2+}-\mathrm{Cl}$ in the square planar $\left[\mathrm{PtCl}_{4}\right]^{2-}$ complexes. Note that during this process no peak corresponding to the Pt-Pt bond was identified in the pair distance distribution. In contrast, $10 \mathrm{~s}$ after initiating the reaction, the peak at $2.77 \AA$ A corresponding to the Pt-Pt bond appeared and the area under the peak started to grow, indicating the formation of Pt NPs. These observations show that the formation of $\mathrm{Pt}$ proceeded in a two-step reduction, within which the second reduction 
step occurred only after the first one was finalized (Fig. 9f).

Intermetallic compounds are distinct from alloys since they display an ordered structure and the synthesis of intermetallic compounds therefore requires a simultaneous co-reduction of metals. This can be achieved by careful selection of metal precursors with comparable reduction rates suggested by in situ X-ray total scattering, as shown by an example presented in the reductive synthesis of $\mathrm{PtPb}$ intermetallic compounds in supercritical ethanol $\left(250-350^{\circ} \mathrm{C}, 25 \mathrm{MPa}\right) . .^{244}$ The areas under the peaks in the PDF corresponding to Pt-O in Pt bis(acetylacetonate) and $\mathrm{Pb}-\mathrm{O}$ in $\mathrm{Pb}$ bis(acetylacetonate) started to decrease at an almost identical rate $20 \mathrm{~s}$ after starting the reaction, suggesting a simultaneous co-reduction of $\mathrm{Pt}$ and $\mathrm{Pb}$ resulting in intermetallic compounds. In contrast, when $\mathrm{H}_{2} \mathrm{PtCl}_{6}$ was taken as the precursor, $\mathrm{Pt}$ was identified in the product. This is due to the much faster reduction rate of $\mathrm{H}_{2} \mathrm{PtCl}_{6}$ than that of $\mathrm{Pt}$ bis(acetylacetonate), as revealed by the peak corresponding to $\mathrm{Pt}-\mathrm{Pt}$ being identified $10 \mathrm{~s}$ after the reaction in the former compared with $20 \mathrm{~s}$ in the latter.

In summary, the need to light up the 'black box' of the synthesis process of metal nanomaterials in supercritical fluids has driven the progress of in situ techniques to follow and optimize the process. Special setups have been constructed that are able to work under supercritical conditions. Established in situ techniques are mostly based on (synchrotron) X-rays as the radiation source thanks to their high energy and good transmission capabilities. In situ X-ray diffraction has been applied in observing the crystallization process of metal nanomaterials, both single metals and alloys, in supercritical fluids with derived information including the intermediate and product crystal phases, crystallite size, population and crystallization rate. As a complement, in situ total X-ray scattering (coupled with pair distribution function analysis, PDF) has been adopted to cover the early stage prior to the crystallization when the structures are highly disordered. The type of atom-atom pair can be identified by the bond distance as the fingerprint, while the presence of a certain pair can be confirmed from the distance distribution analysis.

\section{Supercritical fluid synthesis of functional nanomaterials and its upscaling}

In the above sections, extensive work to date on exploring both the flow and batch processes of supercritical fluid synthesis of non-supported metal nanomaterials has been summarized and reviewed. It is worth mentioning, however, that the non-supported metal nanomaterials only account for a fairly small part in the group of nanomaterials that so far have been synthesized in supercritical fluids. Indeed, the supercritical fluid synthesis technique is expected to play an increasingly important role in the fields of nanomaterials and nanotechnology in the future. ${ }^{150}$

On the one hand, the complex and diverse chemistry processes in the supercritical fluid synthesis of nanomaterials necessitate a combination of tools to study the processes. On the other hand, the versatility of the chemical processes proceeding in supercritical fluids provides opportunities to achieve various types of advanced nanomaterials and nanostructures by design ${ }^{41}$ On this occasion, a few latest examples are highlighted here, in which supercritical fluids are applied as unique reaction media to synthesize nanomaterials other than metal nanomaterials for use in some of the cutting edge technologies including nano semiconductors, quantum dots, graphene and metal-organic frameworks. In particular, note that in most of these examples, the flow process has been adopted to achieve continuous production of the nanomaterials. It means that potentially the synthesis can be scaled up, given the inherent fast reaction and production rates of the flow process in supercritical fluids. In other words, supercritical fluid synthesis can work as a promising solution to address the challenge in the largescale utilization of such advanced nanomaterials, which is often limited by the current conventional synthesis methodologies with a relatively small capacity and thus difficult to be transferred to industrial-level production.

Semiconductor nanocrystals and quantum dots (QDs) with their optoelectronic properties find wide applications in devices such as LEDs and photovoltaic cells and in biomedical imaging. Their optoelectronic properties are highly dependent on the quality of nanocrystals with regard to the uniformity of size, phase and shape. CdSe QDs have been synthesized under supercritical conditions (hexane, $250^{\circ} \mathrm{C}, 10 \mathrm{MPa}$ ) by a flow process at a production rate of $200 \mathrm{mg} \mathrm{h}^{-1}$ in the laboratory. These CdSe QDs display sharp full-width-at-half-maximum (23 nm) and high photoluminescence quantum yields (45-55\%) at $\lambda \sim 425 \mathrm{~nm}$, mainly due to the remarkably narrow size distribution $(2.7 \mathrm{~nm}, \sigma \leq 5 \%)$ with a well-defined crystallinity. ${ }^{66}$ Continuous synthesis of GaN QDs (3.1 nm) has also been conducted in supercritical fluids. A narrower FWHM $(0.5 \mathrm{eV})$ of peaks in photoluminescence emission spectra than usual $(>0.65 \mathrm{eV})$ was achieved as the obtained GaN QDs have a narrow size distribution and high quality. $\underline{\text { - }}$ Synthesis of other types of nanocrystals such as metal sulphides has also been reported by using 
supercritical fluids. In the method of supercritical hydrothermal flow synthesis, a number of metal sulphides different in size and shape have been prepared with thiourea as the sulphur source and supercritical water as the solvent. ${ }^{147,245}$

Supercritical fluids are also applied in preparing graphenic materials via top-down methods such as extraction and exfoliation ${ }^{246-248}$ and bottom-up methods such as supercritical hydrothermal flow synthesis. ${ }^{249-251}$ In this context, single-layer graphene oxide QDs $(2.6 \pm 0.4 \mathrm{~nm}$ in diameter) were obtained by treating anthracite coal in supercritical water $\left(400^{\circ} \mathrm{C}, 25 \mathrm{MPa}\right)$ within only $120 \mathrm{~min}$. A high yield of up to $55 \mathrm{wt} \%$ was achieved and the obtained QDs displayed a high fluorescence quantum yield of $28 \% .246$ Supercritical fluid itself can also participate in the chemical reaction to obtain the graphene derivatives. As an example, $\mathrm{N}$-doped graphene ( $<5$ layers, doping level at 5.1-6.4 atom\%) was prepared by simultaneous exfoliation and N-doping of graphite in supercritical ammonia $\left(200{ }^{\circ} \mathrm{C}, 15 \mathrm{MPa}\right) . .^{247}$ Notably, a rapid and one-pot approach has been employed to synthesize graphene QDs. ${ }^{250,251}$ Graphene oxide and $p$-tetrasulfonic acid calixarene were used as reactants in supercritical water (450 $\left.{ }^{\circ} \mathrm{C}, 24.1 \mathrm{MPa}\right)$ and graphene QDs $(1.8-4.3 \mathrm{~nm})$ in continuous flows with a reaction time of just a few seconds. Metal-organic frameworks (MOFs) are coordinates of metal ions or clusters and ligands in three dimensions, and the coordination networks contain voids. The primary applications of MOFs including gas storage, filtration, heterogeneous catalysis and so on largely rely on the properties of such open frameworks including the porosity, size, connectivity and internal chemical reactivity. ${ }^{148} \mathrm{MOF}$ are typically obtained in the methods of batch solvothermal synthesis lasting for periods of several hours or even days. In comparison, using supercritical fluids under the conditions of high temperature and high pressure significantly enhances the kinetics and thus brings down the time required to form crystallized MOFs. Such an example has been presented in the supercritical hydrothermal flow synthesis of MIL-53(Al), where it lasted only 5-6 min by using supercritical water. Note that in a conventional synthesis method the required time can be up to 3 days. ${ }^{252}$ More examples can be found in other works where a number of MOFs, including HKUST-1 (copper carboxylate), CPO-27 (nickel carboxylate) and $\mathrm{Ce}_{5}(\mathrm{BDC})_{7.5}(\mathrm{DMF})_{4}$ (cerium terephthalate dimethylformamide), ${ }^{252-254}$ have been prepared by using (sub)supercritical fluids in continuous flow in only a few seconds.

Endeavours in upscaling the flow process of supercritical fluid synthesis of nanomaterials have already been observed in a number of research studies. This is mainly related to the supercritical hydrothermal flow synthesis of oxide nanomaterials where supercritical water is applied as the solvent. In the process, oxide nanomaterials are formed in a continuous manner upon mixing two streams of a room-temperature aqueous metal salt solution and supercritical water (type II in Fig. 3). Scaling up the production capacity can be achieved through enlarging the physical dimension of the setup, using the precursor solution at a higher concentration and a higher velocity of streams. However, this brings up some challenges that need to be addressed. The design of the mixer where the mixing and upon which the nucleation and even growth of nanomaterials proceed needs to be validated 255 mainly for two purposes. Firstly, a rapid mixing and thus a homogeneous synthesis environment especially heating and mass transfer need to be preserved to a large extent after scaling up the dimension of the mixer in order to obtain uniform nanomaterials. Secondly, a strong net downstream flow has to be formed to avoid the clogging of the mixer to ensure uninterrupted and efficient production. Another issue comes from the energy utilization efficiency as much energy will be consumed to obtain supercritical water in a large volume. A unit to realize heat recycling thus becomes rather important and necessary in the design of upscaling. To this end, many efforts have been made, and these have led to a pilot-scale supercritical hydrothermal flow synthesis of a number of oxide nanomaterials at a capacity of $2-8 \mathrm{~kg}$ per day. $.56,135,137,155,156,256-262$

In addition to the efforts found in the academic literature, there are also some contributions and progress from industry. The Hanwha Chemical plant in the Republic of Korea is probably the world's first one known to the public to use supercritical hydrothermal flow synthesis to produce $\mathrm{LiFeO}_{4}$ nanomaterials at a full industrial scale (1000 tons per year). ${ }^{263}$ In addition, two groups from the United Kingdom worked separately on projects in which the researchers with their industrial partners designed large pilot plants with a production capacity of tons per year. ${ }^{264,265}$ Notably, a commercial plant has been established as an output of one of the two projects, currently operating at a production level of $>1000$ tons per year. ${ }^{266}$

Given the fact that the supercritical fluid flow synthesis of nanomaterials is growing in the chemical industry, it becomes rather necessary to establish a quantitative tool to evaluate the environment impacts and cost of resources of such a novel technique. Such evaluations are also helpful in improving the competitiveness of this technique compared with the conventional techniques currently applied in producing nanomaterials in industry. Therefore, in the following section, a tool called life cycle assessment (LCA) is introduced which has been used to evaluate the process giving some primary results.

Yu Xu, Valentina Musumeci, Cyril Aymonier. Chemistry in supercritical fluids for the synthesis of metal nanomaterials. Reaction Chemistry \& Engineering, Royal Society of Chemistry, 2019, 4 (12), pp.2030-2054. \{10.1039/C9RE00290A). 〈hal-02393835〉 


\section{Life cycle assessment (LCA)}

Nowadays, achieving sustainable development while limiting the environmental impact is one of the main goals for chemical engineering. In this context, it is essential to establish a method for quantitatively evaluating the environmental impact of a chemical process so that its environmental performance can be improved after identifying the causes of pollution. Green chemistry is defined as the 'design of chemical products and processes to reduce or eliminate the use and generation of hazardous substances' ${ }^{\prime} .67,268$ The principles of green chemistry proposed by Anastas and Warner ${ }^{269}$ and of green engineering proposed by Anastas and Zimmerman ${ }^{270}$ outline the rules to develop safe and environmentally friendly chemical processes. The elimination of hazardous organic solvents and the search for useful non-toxic solvents are the primary goals of green chemistry. $271 \mathrm{In}$ fact, the utilization of solvents is regarded as a major factor when assessing the environmental performance of a chemical process in industry, in addition to the cost, safety and health issues.

In this context, supercritical fluid synthesis has been identified as an inherently sustainable manufacturing method due to the use of moderate reaction temperatures, decreased reaction times and use of "green" solvents. $\mathrm{H}_{2} \mathrm{O}$ and $\mathrm{CO}_{2}$, under their supercritical conditions, are attractive as non-toxic solvents that can substitute noxious organic volatile solvents without further increasing the anthropogenic greenhouse gas emissions. The interest in using supercritical fluids has been recognized by the United States Environmental Protection Agency (US EPA), which promotes competitive incentives to develop environmentally sustainable chemical processes. ${ }^{43,272}$ The applications are broad including synthetic chemistry, waste treatment, materials, semiconductors, energy, pharmaceuticals, medicine, $\mathrm{CO}_{2}$ sequestration, polymers and polymer manufacturing. Most of the projects use $\mathrm{CO}_{2}$; however, a number of them are also using $\mathrm{H}_{2} \mathrm{O}$ since both are compatible with the environment and show enhanced transport properties in reaction and extraction applications.

Before improving the sustainability of a manufacturing route, a question arises firstly: what is the method to evaluate how green the route is? To this end, a comprehensive estimation of the pros and cons of the environmental performances has to be conducted. ${ }^{273}$ Life cycle assessment (LCA) has been defined in the standard guidelines ISO 14040-14044 as 'the compilation and evaluation of the inputs and outputs and the potential impacts of a product system through its life cycle'.274 In this context, LCA is an appropriate tool for a quantitative evaluation of the environmental merits of chemical processes and manufacturing routes. $273,275,276$ All environmental impacts, direct and indirect, associated with the product, synthesis pathway or technology are taken into account in the LCA study. The aim of the analysis encompasses extraction and processing of raw materials, manufacturing and assembly processes, product distribution, use, re-use, maintenance, recycling and disposal. ${ }^{272,277}$ The methodology of LCA involves the iteration of the following steps: (i) goal and scope definition, (ii) life cycle inventory analysis: data collection, (iii) life cycle impact assessment and (iv) life cycle interpretation ${ }^{278}$ (Fig. 10). The results of the LCA analysis are useful for highlighting the attractiveness of the supercritical fluid technology and for identifying where further improvements can be made. 


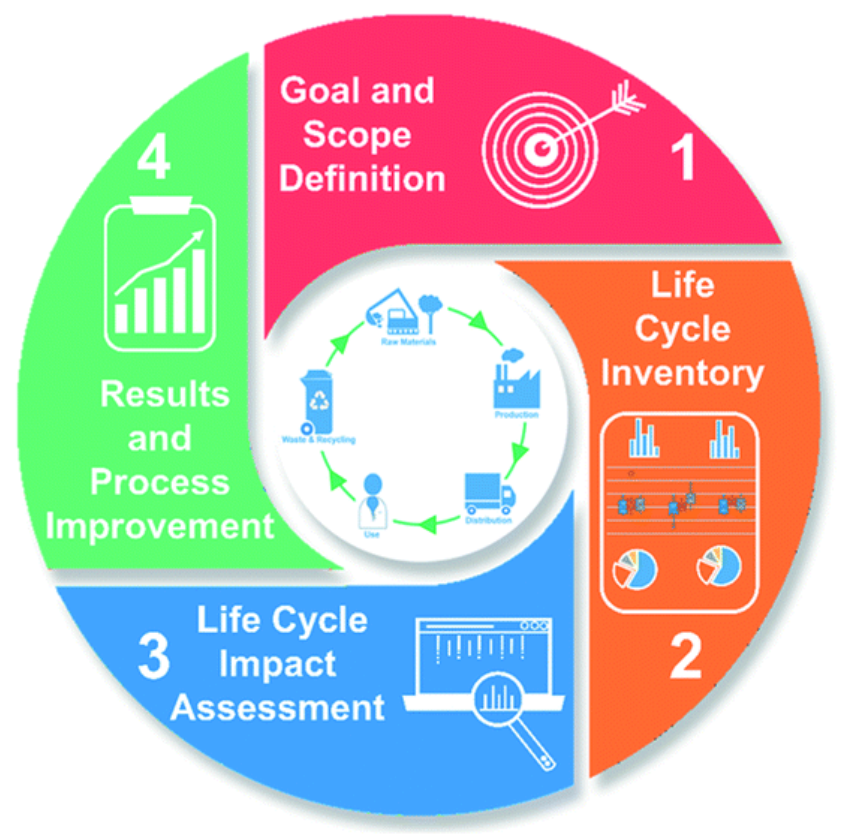

Fig. 10 Scheme of the life cycle assessment (LCA) and methodologies.

To conduct the LCA analysis, the system boundaries have to be defined, including the raw material extraction, material processing, and material production (Fig. 11a). Some contributions to understanding the environmental profile of the supercritical fluid synthesis of nanoparticles have already been made. Tsang et al. ${ }^{152}$ reported the first known attempt to study the environmental impact of the supercritical fluid synthesis by anticipatory LCA using the synthesis of $\mathrm{Ba}_{0.6} \mathrm{Sr}_{0.4} \mathrm{TiO}_{3}$ nanoparticles as a model example. The synthesis was carried out in a continuous reactor by using an ethanol-water mixture at $400{ }^{\circ} \mathrm{C}$ and $23 \mathrm{MPa}$. Fig. $11 \mathrm{~b}$ reports the LCA results of the separate contribution of each life-cycle stage to the total impacts. According to the calculation, nearly $148 \mathrm{~kg}$ of ethanol and $148 \mathrm{~kg}$ of water had to be used as solvents for the production of $1 \mathrm{~kg}$ of nanoparticles. The effects from manufacturing, processing and disposing the ethanol in total contributed on average $90 \%$ and $95 \%$ to the total life-cycle impacts and the global warming potential, respectively. The average contribution from using water was as low as less than $1 \%$ of the total impacts. The life-cycle impact contributions from the use of precursors including barium isopropoxide, strontium isopropoxide and titanium isopropoxide were negligible ( $3 \%)$. The impact contributions of the nanoparticle production steps were divided into the following two: (1) the electricity consumption required to operate the pumps and reactor as well as to increase the temperature of the solvents to their supercritical conditions contributed only $2 \%$ on average to the total impacts; (2) the energy required for drying the resulting nanoparticles contributed less than $1 \%$. The remaining $5 \%$ of impacts on average were attributed to the transportation and other auxiliary factors. It is worth mentioning, however, that the large contributions from the solvents are related to the unoptimized lab-scale setup employed in this study. In contrast, such contributions can be reduced significantly in nanoparticle production in an industrial-scale scenario.

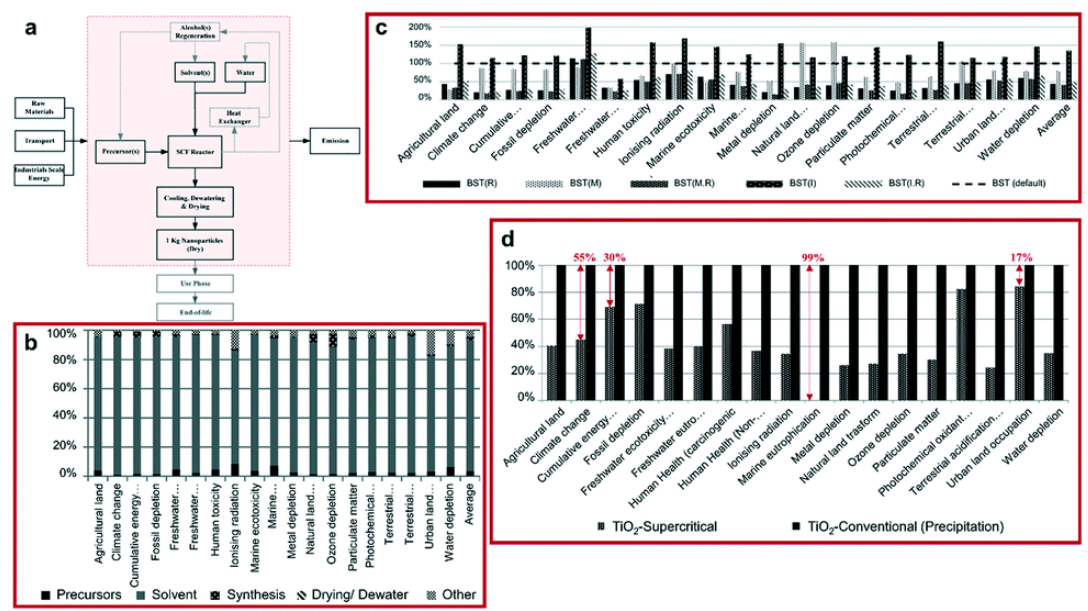

Fig. 11 (a) System boundaries defined for the LCA analysis of the supercritical fluid synthesis of nanoparticles. (b) Contributions from critical life-cycle stages in the default synthesis scenario by using a molar concentration of each precursor of $0.017 \mathrm{~mol} \mathrm{L-1}$ in the ethanol-water solvent mixture. (c) Impact results for the supercritical fluid synthesis route differing in either recycling and/or the solvent type. The default synthesis route uses ethanol and water. Solvent changes are considered only for ethanol; R: recycling, M: methanol and I: isopropanol. (d) Normalized environmental and human health impacts 
corresponding to the production of $1 \mathrm{~kg}$ of nano-TiO2. Note that the resulting impacts for precipitation are set at 100\%. Reprinted with permission from ref. 152. Copyright 2016 Royal Society of Chemistry. Reprinted with permission from ref. 151. Copyright 2018 American Chemical Society.

In this work, the LCA was used to analyse three different solvents (ethanol-water mixture, methanol-water mixture and isopropanol-water mixture) to figure out the one resulting in the lowest environmental impact. It shows that by replacing ethanol with methanol in the alcohol-water mixture it is able to reduce 16 out of the total impact categories under investigation (Fig. 11c). In particular, the climate change potential and cumulative energy demand can be reduced by $13 \%$ and $16 \%$, respectively. In contrast, the use of isopropanol results in greater lifecycle impacts with increases in both the climate change potential and cumulative energy demand of $15 \%$ and $22 \%$, respectively.

Another contribution of conducting the LCA analysis to optimizing the synthesis methodology regards the influences of processes such as the recovery and recycling of materials. Generally, alcohols used as solvents can be collected, distilled and reused, in order to reduce the upstream impacts from producing virgin solvents. Fig. 11c shows that the recycling of ethanol results in reduction of $29 \%$ for ionizing radiation to $80 \%$ for climate change potential. However, the steam formation process used in solvent regeneration results in high levels of air emissions of vanadium from the burning of fuel oil that increases the freshwater eco-toxicity to be $14 \%$ greater than the default scenario.

In another work, LCA was used to investigate the synthesis of $\mathrm{TiO}_{2}$ nanoparticles using an ethanol-water solvent mixture under supercritical conditions. Furthermore, they evaluated the production processes of $\mathrm{TiO}_{2}$ nanoparticles by comparing the supercritical fluid synthesis with the conventional precipitation method. 151 Reductions in impact factors ranging between $17 \%$ for the urban land occupation and up to $99 \%$ for the marine eutrophication can be achieved (Fig. 11d). Specifically, the climate change potential and cumulative energy demand for the supercritical fluid synthesis are $3 \mathrm{~kg} \mathrm{CO}$-eq. per kilogram of $\mathrm{TiO}_{2}$ and $78 \mathrm{MJ}$ per kilogram of $\mathrm{TiO}_{2}$, corresponding to reductions of $55 \%$ and $30 \%$, respectively, compared with those evaluated in the precipitation method. Notably, these values are also considerably lower than the values of $40-75 \mathrm{~kg} \mathrm{CO}$-eq. per kilogram of $\mathrm{TiO}_{2}$ and 920-1550 MJ per kilogram of $\mathrm{TiO}_{2}$ reported in another work using a continuous flow solvothermal synthesis route. ${ }^{154}$ Considering that nearly the same synthesis conditions were applied, these discrepancies might come from the following reasons. Firstly, different solvents were used, namely an ethanol-water mixture ${ }^{151}$ and isopropanol-water. ${ }^{154}$ The use of isopropanol results in a higher environmental impact than using ethanol with increases of $15 \%$ in the climate change potential and $22 \%$ in the cumulative energy demand. Secondly, the concentrations of the precursor solutions were different $\left(1.0 \mathrm{~mol} \mathrm{~L}-1151\right.$ and $0.5 \mathrm{~mol} \mathrm{~L}^{-1}, 154$ respectively). Working at higher concentrations requires less energy and solvent for the same quantity of product particles, thus significantly reducing the environmental impact.

In fact, the environmental impact in an industrial scenario can be further reduced by increasing the precursor concentration and recovering the energy and materials. ${ }^{153,154}$ With these results in mind, to develop a sustainable manufacturing pathway the following points can be advised: (1) life cycle assessment of the process, (2) choosing appropriate chemicals to minimize the environmental issues (e.g., reducing the $\mathrm{CO}_{2}$ footprint), (3) recycling of materials, and (4) combining technological and operational systems to reduce resource and energy.

\section{Conclusion and outlook}

Non-supported metal nanomaterials are interesting to many applications and their properties determine the performances. High controllability, reproducibility and preferably scalability are thus required for the methods applicable to the synthesis and processing of metal nanomaterials. This review provides insights into the advancements and wide versatility of the established methods by using supercritical fluids to design nonsupported metal nanomaterials with desired properties.

The advantages of using supercritical fluids for the synthesis of metal nanomaterials and diversities of chemistry have been shown by means of thermolysis, reductive reactions and microemulsions. A primary relationship has been established for specific cases between properties of the synthesized metal nanomaterials and process parameters including types of precursors and supercritical fluids, temperature, pressure and nature of additives such as reductants and surfactants. In particular, it is notable that the successful adaptation of supercritical fluid synthesis of metal nanomaterials to the flow-type environment may serve as a very promising solution to scaling up the synthesis of metal nanomaterials to a high-throughput level, which has been a limitation for a long time to 
most of the well-established methods for metal nanomaterial synthesis in laboratories. Here, metal nanomaterials can be synthesized continuously in flow streams and the obtained metal nanomaterial colloids can be relatively easily transferred to downstream processes and applications such as printing electronics and flow chemistry catalysis. However, compared with other well-established methods for metal nanomaterial synthesis, few studies have been done in the flow synthesis of metal nanomaterials in supercritical fluids with respect to the relationship between process parameters and properties of metal nanomaterial products. We expect that this will be an interesting topic in the future and thus many studies still need to be conducted in order to clarify the relations so as to achieve customized synthesis of metal nanomaterials in this method. In addition, research studies on transferring the metal nanomaterials in colloids from supercritical fluid synthesis to downstream applications are still scarce.

In situ X-ray characterization techniques have provided valuable and direct observations into the synthesis process of metal nanomaterials especially NPs in supercritical fluids in the very primary stages right after initiating the synthesis and the later steps of nucleation and growth. Current research studies, however, are on rather limited types of metal nanomaterials and supercritical fluids. One of the directions in the future can be adopting in situ techniques to study more types of metal nanomaterials and fluids that are of interest to different applications. Due to the limitations of setups and radiation resources, syntheses for the purpose of conducting in situ characterization hardly mimic the real situations in supercritical fluid syntheses of metal nanomaterials especially those in the flow-type environment. Taking advantage of information obtained in the in situ work to optimize the process conditions in the real synthesis therefore faces restrictions to a certain degree. To address this issue certainly requires improvements in the design of setups or alternatively searching for other types of in situ techniques.

To fully take advantage of the high production rate and efficiency of nanomaterials by using supercritical fluid flow synthesis, scaling up the process while still keeping the uniformity of the synthesized nanomaterials becomes rather important and worthy of study. Such an upscaling has been realized, especially that of supercritical hydrothermal flow synthesis using supercritical water, as pilot-scale plants and even full industrial plants have been established with a production capacity of up to 1000 tons per annum. Nevertheless, it seems that it has still not been used for making metal nanomaterials on such a large scale. In particular, fabricating and stabilizing metal nanomaterial colloids in such a volume would be of significant interest to many applications. Given the infant stage of upscaling the process, further increasing the capacity and diversifying the types of nanomaterials certainly require a close collaboration between chemists and chemical engineers.

Along with bringing the new synthetic technology to industry, it becomes necessary to evaluate its novelty and, more importantly, environmental impacts and sustainability. Life cycle assessment (LCA) analysis has defined the supercritical fluid synthesis as an efficient and environmentally competitive pathway for nanoparticle production. Furthermore, through LCA analysis, the decision-making process (i.e., how well one technology option performs over another) allows one to make this methodology more sustainable as the technology improves.

\section{Acknowledgements}

Y. Xu and C. Aymonier acknowledge support from the French National Research Agency for the funding in the project NanoTrap (Grant No. ANR-17-CE07-0027). V. Musumeci is thankful to the Initiative of Excellence of the University of Bordeaux in the frame of the International Doctoral Program for the financial support. The authors also acknowledge CNRS, the University of Bordeaux, Bordeaux INP and Région Nouvelle Aquitaine.

\section{Notes and references}

1. A. J. Jacobson Chem. Mater., 2010, 22 , 660-674.

2. S. P. Jiang Int. J. Hydrogen Energy, 2012, 37 , 449-470.

3. Z. Zhan, D. M. Bierschenk , J. S. Cronin and S. A. Barnett, Energy Environ. Sci., 2011, 4 , 3951-3954.

4. B. Wang J. Power Sources, 2005, $152,1-15$.

5. A. Morozan , B. Jousselme and S. Palacin , Energy Environ. Sci., 2011, 4, 1238-1254.

6. B. Lim , M. Jiang, P. H. C. Camargo, E. C. Cho, J. Tao , X. Lu , Y. Zhu and Y. Xia, Science, 2009, 324, 1302-1305.

7. N. Yan , C. Zhao , P. J. Dyson, C. Wang , L. Liu and Y. Kou , ChemSusChem, 2008, 1, 626-629.

8. M. J. Hidajat, A. Riaz and J. Kim , Chem. Eng. J., 2018, 348, 799-810.

9. D. Verma , R. Insyani , H. S. Cahyadi , J. Park , S. M. Kim , J. M. Cho , J. W. Bae and J. Kim , Green Chem., 2018, 20, 3253-3270. 
10. N. Yan and P. J. Dyson, Curr. Opin. Chem. Eng., 2013, 2 , 178-183.

11. C. Cheng, D. Shen, S. Gu and K. H. Luo, Catal. Sci. Technol., 2018, 8 , 6275-6296.

12. J. Zhang, J. Teo, X. Chen, H. Asakura, T. Tanaka, K. Teramura and N. Yan , ACS Catal., 2014, 4, 1574-1583.

13. X. Xu , Y. Li , Y. Gong, P. Zhang, H. Li and Y. Wang, J. Am. Chem. Soc., 2012, 134, 16987-16990.

14. S. Sá , H. Silva , L. Brandão, J. M. Sousa and A. Mendes , Appl. Catal., B, 2010, 99 , 43-57.

15. N. Zamel and X. Li , Prog. Energy Combust. Sci., 2011, 37 , 292-329.

16. S. Takenaka, T. Shimizu and K. Otsuka, Int. J. Hydrogen Energy, 2004, $29,1065-1073$.

17. D. Ping , C. Dong , H. Zhao and X. Dong, Ind. Eng. Chem. Res., 2018, 57, 5558-5567.

18. M. Behrens , F. Studt , I. Kasatkin , S. Kühl , M. Hävecker , F. Abild-Pedersen, S. Zander , F. Girgsdies , P. Kurr , B.-L. Kniep , M. Tovar , R. W. Fischer, J. K. Nørskov and R. Schlögl , Science, 2012, 336 , 893-897.

19. S. Zander , E. L. Kunkes, M. E. Schuster , J. Schumann , G. Weinberg , D. Teschner , N. Jacobsen , R. Schlögl and M. Behrens , Angew. Chem., Int. Ed., 2013, 52 , 6536-6540.

20. M. Behrens Angew. Chem., Int. Ed., 2014, 53, 12022-12024.

21. S. Arora and R. Prasad, RSC Adv., 2016, 6, 108668-108688.

22. K. Mette , S. Kühl , H. Düdder , K. Kähler , A. Tarasov , M. Muhler and M. Behrens, ChemCatChem, 2014, 6, 100-104.

23. S. A. Müller , D. Degler, C. Feldmann, M. Türk, R. Moos, K. Fink, F. Studt, D. Gerthsen , N. Bârsan and J.-D. Grunwaldt , ChemCatChem, 2018, $10,864-880$.

24. M. E. Franke, T. J. Koplin and U. Simon, Small, 2006, 2 , 36-50.

25. A. Sanger, A. Kumar, A. Kumar and R. Chandra, Sens. Actuators, B, 2016, 234 , 8-14.

26. A. Star, V. Joshi, S. Skarupo, D. Thomas and J.-C. P. Gabriel , J. Phys. Chem. B, 2006, 110, 21014-21020.

27. S. H. Ko , I. Park , H. Pan , C. P. Grigoropoulos , A. P. Pisano , C. K. Luscombe and J. M. J. Fréchet , Nano Lett., 2007,7 , $1869-1877$.

28. S. Wünscher, R. Abbel, J. Perelaer and U. S. Schubert, J. Mater. Chem. C, 2014, 2 , 10232-10261.

29. C.-J. Jia and F. Schüth, Phys. Chem. Chem. Phys., 2011, 13, 2457-2487.

30. J. Polte CrystEngComm, 2015, $17,6809-6830$.

31. S. Guo and E. Wang, Nano Today, 2011, 6 , 240-264.

32. T. K. Sau and A. L. Rogach, Adv. Mater., 2010, 22 , 1781-1804.

33. A. Chen and C. Ostrom , Chem. Rev., 2015, 115, 11999-12044.

34. Y. Xiong and Y. Xia , Adv. Mater., 2007, 19, 3385-3391.

35. X. Xia , S.-I. Choi , J. A. Herron , N. Lu , J. Scaranto , H.-C. Peng , J. Wang, M. Mavrikakis , M. J. Kim and Y. Xia , J. Am. Chem. Soc., $2013,135,15706-15709$.

36. W. Niu , L. Zhang and G. Xu , ACS Nano, 2010, 4 , 1987-1996.

37. Z. Niu, Q. Peng, M. Gong, H. Rong and Y. Li , Angew. Chem., Int. Ed., 2011, 50, 6315-6319.

38. S. Iravani Green Chem., 2011, 13 , 2638-2650.

39. J. Huang, L. Lin , D. Sun , H. Chen, D. Yang and Q. Li , Chem. Soc. Rev., 2015, 44 , 6330-6374.

40. A. Loppinet-Serani , C. Aymonier and F. Cansell , J. Chem. Technol. Biotechnol., 2010, 85, 583-589.

41. C. Aymonier , G. Philippot , A. Erriguible and S. Marre , J. Supercrit. Fluids, 2018, 134, 184-196.

42. A. Loppinet-Serani, C. Aymonier and F. Cansell, ChemSusChem, 2008, 1, 486-503.

43. H. Machida, M. Takesue and R. L. Smith , J. Supercrit. Fluids, 2011, 60, 2-15.

44. M. Goto J. Supercrit. Fluids, 2009, 47 , 500-507.

45. C. Morin , A. Loppinet-Serani , F. Cansell and C. Aymonier , J. Supercrit. Fluids, 2012, 66 , 232-240.

46. E. W. Lemmon, M. O. McLinden and D. G. Friend, Thermophysical Properties of Fluid Systems, National Institute of Standards and Technology, Gaithersburg MD, 20899, 2019.

47. M. Bondesgaard, J. Becker , J. Xavier , H. Hellstern , A. Mamakhel and B. B. Iversen , J. Supercrit. Fluids, 2016, 113 , 166-197.

48. J. Zhang, S. Ohara, M. Umetsu, T. Naka, Y. Hatakeyama and T. Adschiri , Adv. Mater., 2007, 19, 203-206.

49. C. Slostowski, S. Marre, O. Babot, T. Toupance and C. Aymonier , Langmuir, 2014, 30 , 5965-5972.

50. B. Giroire, C. Slostowski, S. Marre, C. Aymonier, T. Aida, D. Hojo, N. Aoki, S. Takami and T. Adschiri , Phys. Chem. Chem. Phys., 2016, $18,1727-1734$.

51. O. Pascu, L. Marciasini , S. Marre, M. Vaultier, M. Pucheault and C. Aymonier , Nanoscale, 2013, 5, 12425-12431.

52. M. Daschner de Tercero, I. Gonzáles Martínez, M. Herrmann, M. Bruns , C. Kübel , S. Jennewein , U. Fehrenbacher , L. Barner and M. Türk , J. Supercrit. Fluids, 2013, 82 , 83-95.

53. T. Adschiri, K. Kanazawa and K. Arai , J. Am. Ceram. Soc., 1992, 75 , 1019-1022.

54. P. W. Dunne, A. S. Munn, C. L. Starkey, T. A. Huddle and E. H. Lester, Philos. Trans. R. Soc., A, 2015, 373 , 20150015.

55. J. A. Darr, J. Zhang, N. M. Makwana and X. Weng, Chem. Rev., 2017, 117, 11125-11238.

56. M. Claverie, M. Diez-Garcia , F. Martin and C. Aymonier , Chem. - Eur. J., 2019, 25 , 5814-5823.

57. A. Dumas , M. Claverie , C. Slostowski , G. Aubert , C. Careme , C. Le Roux , P. Micoud , F. Martin and C. Aymonier , Angew. Chem., 2016, $128,10022-10025$.

58. M. Diez-Garcia , J. J. Gaitero , J. S. Dolado and C. Aymonier , Angew. Chem., 2017, 129 , 3210-3215.

59. M. Diez-Garcia, J. J. Gaitero, J. I. Santos , J. S. Dolado and C. Aymonier , J. Flow Chem., 2018, 8 , 89-95.

60. A. O'Neil and J. J. Watkins, MRS Bull., 2005, 30, 967-975.

61. M. Türk and C. Erkey , J. Supercrit. Fluids, 2018, 134, 176-183.

62. J. M. Blackburn, D. P. Long, A. Cabañas and J. J. Watkins, Science, 2001, 294, 141-145.

63. S. H. Lee, S. Park, M. Kim , D. Yoon, C. Chanthad, M. Cho, J. Kim , J. H. Park and Y. Lee, Sci. Rep., 2016, $6,32011$.

64. S. Kashiwaya , C. Aymonier , J. Majimel , C. Olivier , A. Klein , W. Jaegermann and T. Toupance, New J. Chem., $2018,42,18649-$ 18658.

65. B. Motos-Pérez, D. Uzio and C. Aymonier, ChemCatChem, 2015, 7 , 3441-3444. 
66. A. Chakrabarty , S. Marre, R. F. Landis, V. M. Rotello, U. Maitra, A. Del Guerzo and C. Aymonier , J. Mater. Chem. C, 2015, 3, 7561-7566.

67. B. Giroire, S. Marre , A. Garcia , T. Cardinal and C. Aymonier, React. Chem. Eng., 2016, 1, 151-155.

68. S. Marre, A. Adamo, S. Basak, C. Aymonier and K. F. Jensen, Ind. Eng. Chem. Res., 2010, 49, 11310-11320.

69. S. Marre, Y. Roig and C. Aymonier , J. Supercrit. Fluids, 2012, 66 , 251-264.

70. S. Marre and C. Aymonier, Topics in Organometallic Chemistry, Springer Verlag, 2016, vol. vol. 57, pp. 177-211.

71. A. K. Goodwin and G. L. Rorrer, Ind. Eng. Chem. Res., 2008, 47, 4106-4114.

72. A. K. Goodwin and G. L. Rorrer, Energy Fuels, 2009, 23 , 3818-825.

73. O. de la Iglesia , V. Sebastián , R. Mallada, G. Nikolaidis , J. Coronas , G. Kolb , R. Zapf , V. Hessel and J. Santamaría , Catal. Today, $2007,125,2-10$.

74. R. Mazurczyk , G. El Khoury, V. Dugas , B. Hannes, E. Laurenceau, M. Cabrera, S. Krawczyk, E. Souteyrand , J. P. Cloarec and Y. Chevolot, Sens. Actuators, B, 2008, $128,552-559$.

75. Y. Kikutani , A. Hibara, K. Uchiyama , H. Hisamoto, M. Tokeshi and T. Kitamori , Lab Chip, 2002, 2, 193-196.

76. R. M. Tiggelaar , F. Benito-López , D. C. Hermes , H. Rathgen , R. J. M. Egberink , F. G. Mugele , D. N. Reinhoudt , A. van den Berg , W. Verboom and H. J. G. E. Gardeniers, Chem. Eng. J., 2007, 131 , 163-170.

77. K. F. Jensen MRS Bull., 2006, 31, 101-107.

78. U. Srinivasan, M. R. Houston, R. T. Howe and R. Maboudian , J. Microelectromech. Syst., 1998, 7 , 252-260.

79. S. A. Kulkarni and K. P. Vijayamohanan, Surf. Sci., 2007, 601, 2983-2993.

80. D. Appelhans, D. Ferse , H.-J. Adler , W. Plieth , A. Fikus , K. Grundke , F.-J. Schmitt , T. Bayer and B. Adolphi , Colloids Surf., A, $2000,161,203-212$.

81. O. Pascu, S. Marre and C. Aymonier, Nanotechnol. Rev., 2015, 4, 487.

82. D. Sanli , S. E. Bozbag and C. Erkey, J. Mater. Sci., 2012, 47 , 2995-3025.

83. S. E. Bozbag, D. Sanli and C. Erkey, J. Mater. Sci., 2012, $47,3469-3492$.

84. S. E. Bozbağ and C. Erkey , J. Supercrit. Fluids, 2015, 96 , 298-312.

85. O. Pascu, S. Moisan, J.-D. Marty and C. Aymonier , J. Phys. Chem. C, 2014, 118, 14017-14025.

86. S. Moisan, J.-D. Marty , F. Cansell and C. Aymonier, Chem. Commun., 2008, 1428-1430.

87. T. Gendrineau, S. Marre, M. Vaultier, M. Pucheault and C. Aymonier , Angew. Chem., Int. Ed., 2012, 51, 8525-8528.

88. A. Kameo, T. Yoshimura and K. Esumi , Colloids Surf., A, 2003, 215 , 181-189.

89. M. C. McLeod, W. F. Gale and C. B. Roberts, Langmuir, 2004, 20, 7078-7082.

90. J.-L. Mi , Y. Shen, J. Becker, M. Bremholm and B. B. Iversen, J. Phys. Chem. C, 2014, 118, 11104-11110.

91. P. S. Shah, S. Husain, K. P. Johnston and B. A. Korgel, J. Phys. Chem. B, 2001, 105, 9433-9440.

92. S. K. Pahari , T. Adschiri and A. B. Panda , J. Mater. Chem., 2011, 21, 10377-10383.

93. H. Choi , B. Veriansyah , J. Kim , J.-D. Kim and J. W. Kang, J. Supercrit. Fluids, 2010, 52, 285-291.

94. J. Kim , D. Kim , B. Veriansyah , J. Won Kang and J.-D. Kim , Mater. Lett., 2009, 63 , 1880-1882.

95. N. M. Dimitrijevic, D. M. Bartels, C. D. Jonah , K. Takahashi and T. Rajh , J. Phys. Chem. B, 2001, 105, 954-959.

96. G. Aksomaityte, M. Poliakoff and E. Lester, Chem. Eng. Sci., 2013, 85 , 2-10.

97. M. Kim , W.-S. Son, K. H. Ahn , D. S. Kim , H. Lee and Y.-W. Lee, J. Supercrit. Fluids, 2014, 90, 53-59.

98. Y.-W. Chih and W.-T. Cheng, Mater. Sci. Eng., B, 2007, 145, 67-75.

99. W.-T. Cheng and Y.-W. Chih, J. Supercrit. Fluids, 2010, 54, 272-280.

100. P. S. Shah , S. Husain , K. P. Johnston and B. A. Korgel , J. Phys. Chem. B, 2002, 106 , 12178-12185.

101. X. Fan, M. C. McLeod, R. M. Enick and C. B. Roberts, Ind. Eng. Chem. Res., 2006, 45 , 3343-3347.

102. S. Yu , S. Li , X. Ge , M. Niu , H. Zhang , C. Xu and W. Li , Ind. Eng. Chem. Res., 2014, 53, 2238-2243.

103. S. Kubota, T. Morioka, M. Takesue, H. Hayashi, M. Watanabe and R. L. Smith , J. Supercrit. Fluids, 2014,86 , 33-40.

104. K. J. Ziegler, R. C. Doty, K. P. Johnston and B. A. Korgel , J. Am. Chem. Soc., 2001, 123, 7797-7803.

105. L. Zhou, S. Wang, H. Ma, S. Ma, D. Xu and Y. Guo, Chem. Eng. Res. Des., 2015, 98, 36-43.

106. M. Bondesgaard, A. Mamakhel, J. Becker , H. Kasai, G. Philippot, M. Bremholm and B. B. Iversen, Chem. Mater., 2017, 29, 3265-3273.

107. S. Desmoulins-Krawiec , C. Aymonier , A. Loppinet-Serani , F. Weill , S. Gorsse , J. Etourneau and F. Cansell , J. Mater. Chem., 2004, $14,228-232$

108. K. Sue, N. Kakinuma, T. Adschiri and K. Arai , Ind. Eng. Chem. Res., 2004, 43 , 2073-2078.

109. K. Sue, A. Suzuki, M. Suzuki , K. Arai , Y. Hakuta , H. Hayashi and T. Hiaki , Ind. Eng. Chem. Res., 2006, 45, 623-626.

110. P. Hald , M. Bremholm , S. B. Iversen and B. B. Iversen , J. Solid State Chem., 2008, 181 , 2681-2683.

111. N. C. Shin, Y.-H. Lee , Y. H. Shin, J. Kim and Y.-W. Lee, Mater. Chem. Phys., 2010, 124, 140-144.

112. G. Seong and T. Adschiri , Dalton. Trans., 2014, 43 , 10778-10786.

113. G. Seong , S. Takami , T. Arita , K. Minami , D. Hojo , A. R. Yavari and T. Adschiri , J. Supercrit. Fluids, 2011, 60 , 113-120.

114. T. Arita , H. Hitaka, K. Minami , T. Naka and T. Adschiri , J. Supercrit. Fluids, 2011, 57, 183-189.

115. X. Lu , K. J. Ziegler, A. Ghezelbash, K. P. Johnston and B. A. Korgel, Nano Lett., 2004, 4 , 969-974.

116. J.-L. Mi , T. N. Jensen , P. Hald , J. Overgaard , M. Christensen and B. B. Iversen , J. Supercrit. Fluids, 2012, 67, 84-88.

117. J.-L. Mi, M. Christensen , C. Tyrsted, K. Ø. Jensen, J. Becker , P. Hald and B. B. Iversen , J. Phys. Chem. C, 2010, 114, 1213312138.

118. K. Esumi , S. Sarashina and T. Yoshimura, Langmuir, 2004, 20 , 5189-5191.

119. K. Saitow, T. Yamamura and T. Minami , J. Phys. Chem. C, 2008, $112,18340-18349$.

120. S. Machmudah , Y. Kuwahara Wahyudiono , M. Sasaki and M. Goto , J. Supercrit. Fluids, 2011, 60 , 63-68.

121. M. B. Plutschack, B. Pieber, K. Gilmore and P. H. Seeberger , Chem. Rev., 2017, 117, 11796-11893. 
122. K. Tedsree, T. Li , S. Jones , C. W. A. Chan , K. M. K. Yu , P. A. J. Bagot , E. A. Marquis , G. D. W. Smith and S. C. E. Tsang , Nat. Nanotechnol., 2011, 6, 302-307.

123. C. S. Yeung and V. M. Dong, Chem. Rev., 2011, $111,1215-1292$.

124. P. Offermans , H. D. Tong , C. J. M. van Rijn , P. Merken , S. H. Brongersma and M. Crego-Calama , Appl. Phys. Lett., 2009, 94 , 223110.

125. G. Li , H. Kobayashi , J. M. Taylor, R. Ikeda , Y. Kubota , K. Kato , M. Takata , T. Yamamoto , S. Toh, S. Matsumura and H. Kitagawa , Nat. Mater., 2014, 13, 802.

126. M. L. De Marco, S. Semlali , B. A. Korgel , P. Barois , G. L. Drisko and C. Aymonier , Angew. Chem., Int. Ed., 2018, 57 , 4478-4498.

127. L. E. Pell , A. D. Schricker , F. V. Mikulec and B. A. Korgel , Langmuir, 2004, 20 , 6546-6548.

128. J. T. Harris, J. L. Hueso and B. A. Korgel , Chem. Mater., 2010, 22 , 6378-6383.

129. J. D. Holmes, K. J. Ziegler, R. C. Doty, L. E. Pell , K. P. Johnston and B. A. Korgel , J. Am. Chem. Soc., 2001, 123, $3743-3748$.

130. C. Aymonier , A. Loppinet-Serani , H. Reverón , Y. Garrabos and F. Cansell , J. Supercrit. Fluids, 2006, 38, 242-251.

131. Y. Xu , N. Farandos, M. Rosa, P. Zielke, V. Esposito, P. Vang Hendriksen, S. H. Jensen , T. Li , G. Kelsall and R. Kiebach , Int. J. Appl. Ceram. Technol., 2018, 15 , 315-327.

132. O. Pascu , S. Marre , C. Aymonier and A. Roig , Nanoscale, 2013, 5 , 2126-2132.

133. D. T. Sawyer and J. L. Roberts, Acc. Chem. Res., 1988, $21,469-476$.

134. D. P. Howard, P. Marchand, L. McCafferty , C. J. Carmalt , I. P. Parkin and J. A. Darr , ACS Comb. Sci., 2017, 19, $239-245$.

135. P. Marchand, N. M. Makwana, C. J. Tighe , R. I. Gruar , I. P. Parkin , C. J. Carmalt and J. A. Darr , ACS Comb. Sci., 2016, 18, 130137.

136. I. D. Johnson, M. Loveridge, R. Bhagat and J. A. Darr , ACS Comb. Sci., 2016, 18, 665-672.

137. D. P. Howard, P. Marchand , I. D. Johnson, C. J. Carmalt , I. P. Parkin and J. A. Darr , J. Mater. Chem. A, 2016, 4, 12774-12780.

138. X. Weng , J. K. Cockcroft, G. Hyett, M. Vickers, P. Boldrin , C. C. Tang, S. P. Thompson , J. E. Parker , J. C. Knowles, I. Rehman , I. Parkin , J. R. G. Evans and J. A. Darr , J. Comb. Chem., 2009, 11 , 829-834.

139. Y. Yang , T. Lin , X. L. Weng , J. A. Darr and X. Z. Wang , Comput. Chem. Eng., 2011, $35,671-678$.

140. C. Slostowski , S. Marre, J.-M. Bassat and C. Aymonier , J. Supercrit. Fluids, 2013, 84, 89-97.

141. A. Nugroho and J. Kim , J. Ind. Eng. Chem., 2014, 20 , 4443-4446.

142. M. J. Powell , P. Marchand , C. J. Denis , J. C. Bear , J. A. Darr and I. P. Parkin , Nanoscale, 2015, 7 , 18686-18693.

143. Y. Shen, J. R. Eltzholtz and B. B. Iversen, Chem. Mater., 2013, 25 , 5023-5030.

144. Y. Xu, S. Pirou, P. Zielke, S. B. Simonsen, P. Norby, P. V. Hendriksen and R. Kiebach, Ind. Eng. Chem. Res., 2018, 57, 2123-2130.

145. O. Pascu , S. Marre , B. Cacciuttolo , G. Ali , L. Hecquet, M. Pucheault , V. Prevot and C. Aymonier , ChemNanoMat, 2017, 3 , 614619.

146. Q. Wang , S. V. Y. Tang , E. Lester and D. O'Hare , Nanoscale, 2013, 5 , 114-117.

147. P. W. Dunne , C. L. Starkey, M. Gimeno-Fabra and E. H. Lester, Nanoscale, 2014, 6 , 2406-2418.

148. P. W. Dunne, E. Lester and R. I. Walton, React. Chem. Eng., 2016, 1, 352-360.

149. T. Adschiri , Y. Hakuta, K. Sue and K. Arai , J. Nanopart. Res., 2001, 3 , 227-235.

150. T. Adschiri and A. Yoko , J. Supercrit. Fluids, 2018, 134, 167-175.

151. M. P. Tsang, G. Philippot, C. Aymonier and G. Sonnemann , ACS Sustainable Chem. Eng., 2018, 6, 5142-5151.

152. M. Tsang, G. Philippot, C. Aymonier and G. Sonnemann, Green Chem., 2016, 18 , 4924-4933.

153. P. Caramazana, P. Dunne, M. Gimeno-Fabra , J. McKechnie and E. Lester ,Curr. Opin. Green Sustain. Chem., 2018,12 , 57-62.

154. P. Caramazana-González, P. W. Dunne, M. Gimeno-Fabra, M. Zilka, M. Ticha, B. Stieberova, F. Freiberg, J. McKechnie and E. H. Lester, Green Chem., 2017, 19 , 1536-1547.

155. R. I. Gruar , C. J. Tighe and J. A. Darr, Ind. Eng. Chem. Res., 2013, 52 , 5270-5281.

156. P. W. Dunne, C. L. Starkey , A. S. Munn, S. V. Y. Tang, O. Luebben, I. Shvets, A. G. Ryder , Y. Casamayou-Boucau , L. Morrison and E. H. Lester, Chem. Eng. J., 2016, $289,433-441$.

157. T. Arita , H. Hitaka, K. Minami , T. Naka and T. Adschiri , Chem. Lett., 2011, 40 , 588-590.

158. C. Wu , B. P. Mosher, K. Lyons and T. Zeng, J. Nanosci. Nanotechnol., 2010, 10, 2342-2347.

159. K. M. Koczkur, S. Mourdikoudis, L. Polavarapu and S. E. Skrabalak, Dalton. Trans., 2015, 44, 17883-17905.

160. R. Eluri and B. Paul , J. Nanopart. Res., 2012, $14,800$.

161. J. Yu and P. E. Savage, Ind. Eng. Chem. Res., 1998, 37 , 2-10.

162. D. F. Shriver and P. W. Atkins, Inorganic Chemistry, Oxford: Oxford University Press, New York, 2006.

163. H. Hayashi and Y. Hakuta, Materials, 2010, 3 , 3794-3817.

164. E. Roduner Chem. Soc. Rev., 2006, 35, 583-592.

165. J. M. DeSimone Science, 2002, 297 , 799-803.

166. X. Han and M. Poliakoff, Chem. Soc. Rev., 2012, 41 , 1428-1436.

167. X. Zhang , S. Heinonen and E. Levänen, RSC Adv., 2014, 4, 61137-61152.

168. J. Liu , Y. Ikushima and Z. Shervani , Curr. Opin. Solid State Mater. Sci., 2003, 7 , 255-261.

169. J. Liu, P. Raveendran , Z. Shervani, Y. Ikushima and Y. Hakuta, Chem. - Eur. J., 2005, 11 , 1854-1860.

170. R. Shimizu , A. Nibe, K. Sawada, Y. Enokida and I. Yamamoto, J. Supercrit. Fluids, 2008, 44, 109-114.

171. M. C. McLeod, R. S. McHenry, E. J. Beckman and C. B. Roberts, J. Phys. Chem. B, 2003, 107, 2693-2700.

172. N. Kometani , Y. Toyoda, K. Asami and Y. Yonezawa, Chem. Lett., 2000, 682-683.

173. Y.-P. Sun , P. Atorngitjawat and M. J. Meziani , Langmuir, 2001, 17 , 5707-5710.

174. H. Ohde, F. Hunt and C. M. Wai, Chem. Mater., 2001, 13, 4130-4135.

175. H. Ohde, C. M. Wai , H. Kim , J. Kim and M. Ohde , J. Am. Chem. Soc., 2002, 124 , 4540-4541.

176. L. Lu and X. An , J. Supercrit. Fluids, 2015, $99,29-37$.

177. C. A. Fernandez and C. M. Wai, Small, 2006, 2 , 1266-1269. 
178. N. Kometani , M. Kaneko, T. Morita and Y. Yonezawa , Colloids Surf., A, 2008, 321 , 301-307.

179. Y. Zong and J. J. Watkins, Chem. Mater., 2005, 17 , 560-565.

180. M. Haruki , S. Li , G. Qian and J. J. Watkins, J. Supercrit. Fluids, 2016, 107 , 189-195.

181. E. Kondoh and H. Kato , Microelectron. Eng., 2002, 64 , 495-499.

182. T. Momose, M. Sugiyama , E. Kondoh and Y. Shimogaki , Appl. Phys. Express, 2008, 1, 0970021-0970023.

183. T. Momose, M. Sugiyama and Y. Shimogak, Jpn. J. Appl. Phys., Part 2, 2005, 44 , L1199-L1202.

184. B. Giroire, M. Ali Ahmad, G. Aubert , L. Teule-Gay, D. Michau, J. J. Watkins , C. Aymonier and A. Poulon-Quintin , Thin Solid Films, 2017, 643, 53-59.

185. D. P. Long, J. M. Blackburn and J. J. Watkins, Adv. Mater., 2000, 12 , 913-915.

186. J. M. Blackburn , D. P. Long and J. J. Watkins, Chem. Mater., 2000, 12 , 2625-2631.

187. A. Cabañas, J. M. Blackburn and J. J. Watkins, Microelectron. Eng., 2002, 64, 53-61.

188. A. Cabañas, X. Shan and J. J. Watkins , Chem. Mater., 2003, 15 , 2910-2916.

189. A. Cabañas, D. P. Long and J. J. Watkins , Chem. Mater., 2004, 16 , 2028-2033.

190. E. T. Hunde and J. J. Watkins, Chem. Mater., 2004, 16, 498-503.

191. A. O'Nei and J. J. Watkins, Chem. Mater., 2006, 18, 5652-5658.

192. G. Collins, M. Koleśnik, V. Krstić and J. D. Holmes, Chem. Mater., 2010, 22 , 5235-5243.

193. K. J. Ziegler , P. A. Harrington , K. M. Ryan , T. Crowley , J. D. Holmes and M. A. Morris , J. Phys.: Condens. Matter, 2003,15 , 83038314.

194. H. Wakayama and Y. Fukushima, Chem. Commun., 1999, 391-392.

195. H. Wakayama, T. Hatanaka and Y. Fukushima, Chem. Lett., 2004, 33, 658-659.

196. R. Morrish and A. J. Muscat, Chem. Mater., 2009, 21 , 3865-3870.

197. R. Morrish and A. J. Muscat, J. Phys. Chem. C, 2013, 117, 12071-12077.

198. Y. C. Liu , J. C. Huang, X. Wang, M. T. Tsai and Z. K. Wang, RSC Adv., 2018, 8, 13075-13082.

199. A. Denis , E. Sellier , C. Aymonier and J.-L. Bobet, J. Alloys Compd., 2009, 476, 152-159.

200. C. Aymonier, A. Denis , Y. Roig , M. Iturbe , E. Sellier , S. Marre , F. Cansell and J. L. Bobet, J. Supercrit. Fluids, 2010, 53, 102-107.

201. M. Majimel , S. Marre, E. Garrido and C. Aymonier, Chem. Vap. Deposition, 2011, 17 , 342-352.

202. E. Garrido , C. Aymonier , L. Roiban , O. Ersen , C. Labrugère , P. Gaillard and M. Lamirand-Majimel , J. Supercrit. Fluids, 2015, 101, $110-116$.

203. J. Morère, M. J. Torralvo , C. Pando , J. A. R. Renuncio and A. Cabañas , RSC Adv., 2015, 5 , 38880-38891.

204. B. Cangül , L. C. Zhang, M. Aindow and C. Erkey, J. Supercrit. Fluids, 2009, 50, 82-90.

205. S. Wolff, M. Crone , T. Muller, M. Enders, S. Bräse and M. Türk , J. Supercrit. Fluids, 2014, 95 , 588-596.

206. J. Zhao , L. Zhang, T. Chen , H. Yu , L. Zhang, H. Xue and H. Hu , J. Phys. Chem. C, 2012, 116, 21374-21381.

207. T. Shimizu , I. Ushiki , M. Ota , Y. Sato , N. Koizumi and H. Inomata , Chem. Eng. Res. Des., 2015, 95, 64-68.

208. X. Liu , W. Liu , J. Li , Y. Zhang, L. Lang , L. Ma and B. Zhang, Ind. Eng. Chem. Res., 2010, 49, 8826-8831.

209. Y. Meng, F. Su and Y. Chen, ACS Appl. Mater. Interfaces, 2017, 9 , 39549-39559.

210. C. Erkey J. Supercrit. Fluids, 2009, 47 , 517-522.

211. Z. Liu and B. Han , Adv. Mater., 2009, 21 , 825-829.

212. S. Marre, F. Cansell and C. Aymonier, Nanotechnology, 2006, 17 , 4594-4599.

213. J. L. Bobet , C. Aymonier , D. Mesguich , F. Cansell , K. Asano and E. Akiba , J. Alloys Compd., 2007, 429, $250-254$.

214. S. Marre, A. Erriguible, A. Perdomo , F. Cansell , F. Marias and C. Aymonier, J. Phys. Chem. C, 2009, 113, 5096-5104.

215. J.-Z. Yin and C.-S. Tan , Fluid Phase Equilib., 2006, 242 , 111-117.

216. H. M. Woods, M. M. C. G. Silva, C. Nouvel , K. M. Shakesheff and S. M. Howdle, J. Mater. Chem., 2004, 14, 1663-1678.

217. T. Luo , J. Zhang, X. Tan , C. Liu , T. Wu , W. Li , X. Sang , B. Han , Z. Li , G. Mo , X. Xing and Z. Wu , Angew. Chem., Int. Ed., 2016,55 , 13533-13537.

218. H. Jensen, M. Bremholm , R. P. Nielsen, K. D. Joensen, J. S. Pedersen , H. Birkedal , Y.-S. Chen , J. Almer , E. G. Søgaard , S. B. Iversen and B. B. Iversen, Angew. Chem., Int. Ed., 2007, 46, 1113-1116.

219. M. Bremholm , H. Jensen, S. B. Iversen and B. B. Iversen , J. Supercrit. Fluids, 2008, 44 , 385-390.

220. J. Becker, M. Bremholm , C. Tyrsted , B. Pauw , K. M. O. Jensen , J. Eltzholt , M. Christensen and B. B. Iversen , J. Appl. Crystallogr., 2010, $43,729-736$.

221. T. Beuvier , E. A. C. Panduro, P. Kwaśniewski , S. Marre , C. Lecoutre , Y. Garrabos , C. Aymonier , B. Calvignac and A. Gibaud , Lab Chip, 2015, $15,2002-2008$.

222. V. Middelkoop, P. Boldrin , M. Peel , T. Buslaps, P. Barnes , J. A. Darr and S. D. M. Jacques, Chem. Mater., 2009, 21 , $2430-2435$.

223. T. Fujita, H. Kasai and E. Nishibori , J. Supercrit. Fluids, 2019, 147, 172-178.

224. A. Yoko, M. Akizuki , N. Hirao , S. Kohara, M. Kumar , N. Umezawa , T. Ohno and Y. Oshima , J. Supercrit. Fluids, 2016, 107, 746752.

225. M. Dreher, E. De Boni , M. Nachtegaal , J. Wambach and F. Vogel , Rev. Sci. Instrum., 2012, 83, 054101.

226. G. Philippot, E. D. Boejesen, C. Elissalde , M. Maglione , C. Aymonier and B. B. Iversen , Chem. Mater., 2016, 28, $3391-3400$.

227. T. Voisin , A. Erriguible , G. Philippot , D. Ballenghien, D. Mateos , F. Cansell , B. B. Iversen and C. Aymonier , Chem. Eng. Sci., $2017,174,268-276$.

228. V. Middelkoop , C. J. Tighe , S. Kellici , R. I. Gruar, J. M. Perkins, S. D. M. Jacques , P. Barnes and J. A. Darr , J. Supercrit. Fluids, 2014, $87,118-128$.

229. S. Birgisson, D. Saha and B. B. Iversen, Cryst. Growth Des., 2018, 18, 827-838.

230. D. Saha , K. M. Ø. Jensen , C. Tyrsted , E. D. Bøjesen , A. H. Mamakhel , A.-C. Dippel , M. Christensen and B. B. Iversen , Angew. Chem., Int. Ed., 2014, 53 , 3667-3670. 
231. J. R. Eltzholtz , C. Tyrsted , K. M. Ø. Jensen, M. Bremholm , M. Christensen , J. Becker-Christensen and B. B. Iversen , Nanoscale, $2013,5,2372-2378$.

232. M. Bremholm , J. Becker-Christensen and B. B. Iversen , Adv. Mater., 2009, 21 , 3572-3575.

233. M. Bremholm , M. Felicissimo and B. B. Iversen, Angew. Chem., Int. Ed., 2009, 48, 4788-4791.

234. C. Tyrsted, J. Becker , P. Hald, M. Bremholm , J. S. Pedersen, J. Chevallier , Y. Cerenius , S. B. Iversen and B. B. Iversen, Chem. Mater., 2010, 22 , 1814-1820.

235. P. Nørby , M. Roelsgaard, M. Søndergaard and B. B. Iversen ,Cryst. Growth Des., 2016, $16,834-841$.

236. P. Nørby , K. M. Ø. Jensen, N. Lock , M. Christensen and B. B. Iversen, RSC Adv., 2013, 3 , 15368-15374.

237. M. Besnard , T. Tassaing , Y. Danten , J.-M. Andanson, J.-C. Soetens , F. Cansell , A. Loppinet-Serani , H. Reveron and C. Aymonier , J. Mol. Liq., 2006, 125 , 88-99.

238. N. Liu , C. Aymonier , C. Lecoutre, Y. Garrabos and S. Marre, Chem. Phys. Lett., 2012, 551, 139-143.

239. P. Vitoux, T. Tassaing , F. Cansell , S. Marre and C. Aymonier, J. Phys. Chem. B, 2009, 113, 897-905.

240. B. Pinho, S. Girardon , F. Bazer-Bachi , G. Bergeot, S. Marre and C. Aymonier , Lab Chip, 2014, 14, 3843-3849.

241. J.-L. Mi , H. F. Clausen, M. Bremholm , M. S. Schmøkel , P. Hernández-Fernández , J. Becker and B. B. Iversen , Chem. Mater., 2015, $27,450-456$.

242. J.-L. Mi , P. Nørby , M. Bremholm , J. Becker and B. B. Iversen, Nanoscale, 2015, 7 , 16170-16174.

243. D. Saha, E. D. Bøjesen, K. M. Ø. Jensen, A.-C. Dippel and B. B. Iversen , J. Phys. Chem. C, 2015, 119, 13357-13362.

244. D. Saha, E. D. Bøjesen, A. H. Mamakhel, M. Bremholm and B. B. Iversen , ChemNanoMat, 2017, 3, 472-478.

245. P. W. Dunne, A. S. Munn, C. L. Starkey and E. H. Lester, Chem. Commun., 2015, 51, 4048-4050.

246. S. P. Sasikala , L. Henry , G. Yesilbag Tonga , K. Huang , R. Das , B. Giroire, S. Marre, V. M. Rotello, A. Penicaud , P. Poulin and C. Aymonier , ACS Nano, 2016, $10,5293-5303$.

247. S. P. Sasikala , K. Huang, B. Giroire, P. Prabhakaran, L. Henry, A. Penicaud, P. Poulin and C. Aymonier, ACS Appl. Mater. Interfaces, 2016, 8, 30964-30971.

248. S. Padmajan Sasikala , P. Poulin and C. Aymonier , Adv. Mater., 2016, 28 , 2663-2691.

249. S. Kellici , J. Acord , J. Ball , H. S. Reehal , D. Morgan and B. Saha, RSC Adv., 2014, 4 , 14858-14861.

250. S. Kellici, J. Acord, N. P. Power, D. J. Morgan, P. Coppo , T. Heil and B. Saha, RSC Adv., 2017, 7 , 14716-14720.

251. S. Kellici , J. Acord, K. E. Moore, N. P. Power , V. Middelkoop , D. J. Morgan, T. Heil , P. Coppo , I.-A. Baragau and C. L. Raston , React. Chem. Eng., 2018, 3, 949-958.

252. P. A. Bayliss , I. A. Ibarra, E. Pérez, S. Yang , C. C. Tang , M. Poliakoff and M. Schröder , Green Chem., 2014, 16, $3796-3802$.

253. M. Gimeno-Fabra, A. S. Munn , L. A. Stevens , T. C. Drage , D. M. Grant , R. J. Kashtiban , J. Sloan , E. Lester and R. I. Walton , Chem. Commun., 2012, $48,10642-10644$.

254. L. D'Arras , C. Sassoye , L. Rozes, C. Sanchez , J. Marrot , S. Marre and C. Aymonier , New J. Chem., 2014, 38 , $1477-1483$.

255. C. Y. Ma , J. J. Liu , Y. Zhang and X. Z. Wang , J. Supercrit. Fluids, 2015, 98 , 211-221.

256. N. M. Makwana, C. J. Tighe, R. I. Gruar, P. F. McMillan and J. A. Darr, Mater. Sci. Semicond. Process., 2016, 42, $131-137$.

257. I. D. Johnson, E. Blagovidova , P. A. Dingwall , D. J. L. Brett , P. R. Shearing and J. A. Darr , J. Power Sources, 2016,326 , 476-481.

258. C. J. Tighe, R. Q. Cabrera, R. I. Gruar and J. A. Darr, Ind. Eng. Chem. Res., 2013, 52 , 5522-5528.

259. L. Shi , A. J. T. Naik , J. B. M. Goodall , C. Tighe , R. Gruar , R. Binions , I. Parkin and J. Darr , Langmuir, 2013, 29, $10603-10609$.

260. R. I. Gruar, C. J. Tighe, P. Southern, Q. A. Pankhurst and J. A. Darr , Ind. Eng. Chem. Res., 2015, 54, 7436-7451.

261. A. J. T. Naik , R. Gruar , C. J. Tighe , I. P. Parkin , J. A. Darr and R. Binions, Sens. Actuators, B, 2015, 217, 136-145.

262. I. D. Johnson, M. Lübke, O. Y. Wu, N. M. Makwana, G. J. Smales, H. U. Islam , R. Y. Dedigama, R. I. Gruar , C. J. Tighe , D. O. Scanlon , F. Corà , D. J. L. Brett , P. R. Shearing and J. A. Darr , J. Power Sources, 2016, 302 , 410 -418.

263. T. Adschiri , Y.-W. Lee , M. Goto and S. Takami , Green Chem., 2011, 13, $1380-1390$.

264. Continuous Hydrothermal Synthesis of Nanomaterials: From Laboratory to Pilot Plant, (n.d.), https://gow.epsrc.ukri.org/NGBOViewGrant.aspx?GrantRef=EP/E040551/1 (accessed June 17, 2019).

265. Sustainable Hydrothermal Manufacturing of Nanomaterials|Projects|FP7|CORDIS|European Commission, (n.d.), https://cordis.europa.eu/project/rcn/103330/factsheet/en.

266. Promethean Particles Ltd|Formulating solutions with nanomaterials, Promethean Part. (n.d.), https://www.prometheanparticles.co.uk/ (accessed June 17, 2019).

267. P. Anastas and N. Eghbali, Chem. Soc. Rev., 2010, 39 , 301-312.

268. I. T. Horváth and P. T. Anastas, Chem. Rev., 2007, 107, 2169-2173.

269. P. Anastas and J. Warner, Green Chemistry: Theory and Practice, Oxford University Press, Oxford, New York, 2000.

270. P. T. Anastas and J. B. Zimmerman , Environ. Sci. Technol., 2003, 37 , 94A-101A.

271. C. Capello, U. Fischer and K. Hungerbühler, Green Chem., 2007, 9, 927-934.

272. US EPA, US EPA. (n.d.). https://www.epa.gov/ (accessed June 14, 2019).

273. M. P. Tsang , E. Kikuchi-Uehara , G. W. Sonnemann , C. Aymonier and M. Hirao , Nat. Nanotechnol., 2017, 12 , 734.

274. ISO 14040:2006(en), Environmental management - Life cycle assessment - Principles and framework, (n.d.), https://www.iso.org/obp/ui/\#iso:std:iso:14040:ed-2:v1:en (accessed June 14, 2019).

275. M. Lotteau , P. Loubet , M. Pousse , E. Dufrasnes and G. Sonnemann , Build. Environ., 2015, 93 , 165-178.

276. H. L. Pesonen , T. Ekvall , G. Fleischer, G. Huppes, C. Jahn , Z. S. Klos, G. Rebitzer , G. W. Sonnemann , A. Tintinelli , B. P. Weidema and $\mathrm{H}$. Wenzel , Int. J. Life Cycle Assess., 2000, 5, 21-30.

277. A. A. Burgess and D. J. Brennan , Chem. Eng. Sci., 2001, 56 , 2589-2604.

278. D. Kralisch , D. Ott and D. Gericke, Green Chem., 2015, 17, 123-145. 